\title{
Pre-clinical models of small cell lung cancer and the validation of therapeutic targets
}

Jane S.Y. Sui

St James's Hospital, Dublin

Petra Martin

St James's Hospital, Dublin

Steven G. Gray

Technological University Dublin, sgray@stjames.ie

Follow this and additional works at: https://arrow.tudublin.ie/scschbioart

Part of the Oncology Commons

\section{Recommended Citation}

Jane S. Y. Sui, Petra Martin \& Steven G. Gray (2020) Pre-clinical models of small cell lung cancer and the validation of therapeutic targets, Expert Opinion on Therapeutic Targets, 24:3, 187-204, DOI: 10.1080/ 14728222.2020 .1732353

This Article is brought to you for free and open access by the School of Biological Sciences at ARROW@TU Dublin. It has been accepted for inclusion in Articles by an authorized administrator of ARROW@TU Dublin. For more information, please contact arrow.admin@tudublin.ie, aisling.coyne@tudublin.ie,gerard.connolly@tudublin.ie.

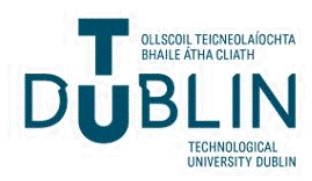




\title{
Pre-clinical models of small cell lung cancer and the validation of therapeutic targets
}

\author{
Jane S. Y. Sui, Petra Martin \& Steven G. Gray
}

To cite this article: Jane S. Y. Sui, Petra Martin \& Steven G. Gray (2020) Pre-clinical models of small cell lung cancer and the validation of therapeutic targets, Expert Opinion on Therapeutic Targets, 24:3, 187-204, DOI: 10.1080/14728222.2020.1732353

To link to this article: https://doi.org/10.1080/14728222.2020.1732353

册 Published online: 26 Feb 2020.

Submit your article to this journal $₫$

山ll Article views: 228

Q View related articles ¿

View Crossmark data

Citing articles: 2 View citing articles 


\title{
Pre-clinical models of small cell lung cancer and the validation of therapeutic targets
}

\author{
Jane S. Y. Sui ${ }^{\mathrm{a}, \mathrm{b}}$, Petra Martin ${ }^{\mathrm{a}}$ and Steven G. Gray $\mathbb{1}^{\mathrm{a}, \mathrm{c}, \mathrm{d}}$ \\ ${ }^{a}$ Thoracic Oncology Research Group, Laboratory Medicine and Molecular Pathology, Central Pathology Laboratory, St. James's Hospital, Dublin, \\ Ireland; 'Department of Medical Oncology, Mater Misericordiae University Hospital, Dublin, Ireland; 'Labmed Directorate, St. James's Hospital, \\ Dublin, Ireland; 'School of Biological Sciences, Dublin Institute of Technology, Dublin, Ireland
}

\begin{abstract}
Introduction: Small-cell lung cancer (SCLC) is an aggressive form of lung cancer that has a dismal prognosis. One of the factors hindering therapeutic developments for SCLC is that most SCLC is not surgically resected resulting in a paucity of material for analysis. To address this, significant efforts have been made by investigators to develop pre-clinical models of SCLC allowing for downstream target identification in this difficult to treat cancer.

Areas covered: In this review, we describe the current pre-clinical models that have been developed to interrogate SCLC, and outline the benefits and limitations associated with each. Using examples we show how each has been used to (i) improve our knowledge of this intractable cancer, and (ii) identify and validate potential therapeutic targets that (iii) are currently under development and testing within the clinic.

Expert opinion: The large numbers of preclinical models that have been developed have dramatically improved the ways in which we can examine SCLC and test therapeutic targets/interventions. The newer models are rapidly providing novel avenues for the design and testing of new therapeutics. Despite this many of these models have inherent flaws that limit the possibility of their use for individualized therapy decision-making for SCLC.
\end{abstract}

ARTICLE HISTORY

Received 30 September 2019 Accepted 17 February 2020

KEYWORDS

Small-cell lung cancer (SCLC); pre-clinical models; heterogeneity; drug resistance; liquid biopsy

\section{Introduction}

Small-cell lung cancer (SCLC) is an aggressive poorly differentiated neuroendocrine tumor accounts for $13 \%$ of all lung cancer cases [1]. It is one of the poorest survival rates of lung cancer, with median overall survival of approximately 10 months. At diagnosis, patients tend to present with widely metastatic disease due to rapid growth and doubling time of tumor proliferation [2-4]. SCLC occurs almost exclusively in smokers especially in heavy smokers [5], and in the Western world, the incidence of SCLC has decreased due to smoking pattern and smoking cessation programs [5].

The first staging system for SCLC was introduced by the Veterans' Administration Lung Study Group (VALSG) [6]. Staging was divided into two disease subgroups termed 'limited-stage' characterized by tumors confined to one radiation portal although local extension into ipsilateral, supraclavicular nodes could be present and 'extensive-stage' for extrathoracic metastases. In 2007, the International Association for the Study of Lung Cancer (IASLC) recommended that the seventh edition of the American Joint Committee on Cancer Staging (AJCC) and the Union Internationale Contre le Cancer (UICC) tumor, node, metastasis (TNM) staging should replace the VALSG staging system [7]. Now superseded by the 8th edition, the IASLC Lung Cancer Staging Project allows an accurate staging of SCLC with TNM, which carries important prognostic outcomes and implications for treatment in SCLC [8].
Whilst this staging system is critical to patient care, other attempts to stratify SCLC into different subgroups based on our molecular understanding of SCLC have been attempted, and were most recently discussed in depth and synthesized into a working nomenclature for SCLC based upon the expression of four key transcriptional regulators [9].

SCLC is highly responsive to cytotoxic chemotherapy in early lines of therapy $[9,10]$. One third of SCLC presents with early-stage disease which can be cured with surgery or concomitant cytotoxic chemotherapy with radiotherapy [10]. However, the majority of SCLC has short duration of response to therapy due to acquired therapeutic resistance with 5-year survival rates less than 7\% [11].

Pre-clinical models with SCLC often show promising therapeutic possibilities. However, most often these fail to translate into clinical benefits in phase II/III clinical trials, and a salutary reminder of this in SCLC has been the discontinuation of Rova-T [12] a drug that showed exciting potential in pre-clinical models of SCLC (discussed in more detail in section 3.2). Over the last four decades, the standard treatment for SCLC has not changed with regimen consistent with platinum-based agent (cisplatin or carboplatin) in combination with etoposide [13]. Most recently, a breakthrough for treatment of SCLC involved the incorporation of the immune checkpoint inhibitor atezolizumab, 


\section{Article Highlights}

- Small-cell Lung Cancer (SCLC) is an aggressive tumor with poor prognosis, characterized by the development of rapid resistance to chemotherapy.

- As surgical intervention is rare for SCLC, hypothesis testing has been hampered by a lack of available material.

- The development of pre-clinical models has allowed the identification and pre-clinical testing of novel new agents and therapeutic targets.

- Limitations exist for many of these models which preclude testing patients for individualized therapy although advances in this area suggest that this barrier may be overcome.

- Blood-based pre-clinical models may hold the key to this strategy allowing for ex vivo expansion of patients' tumor cells allowing for testing of samples for personalized therapy.

This box summarizes key points contained in the article.

targeting programmed cell death ligand-1 (PD-L1), into standard first-line therapy with carboplatin and etoposide for initial treatment for extensive-stage SCLC which showing a median improvement of overall survival by 2 months [14], leading to Food and Drug Administration (FDA) approval of this combination for extensive-disease-smallcell lung cancer (ED-SCLC) in March 2019 [15], but costbenefit analysis suggests that such a treatment regimen is not cost-effective choice in the first-line setting [16]. However, a more recent analysis of the IMpower133 study with respect to adverse events (AEs) and patientreported outcomes suggest that a positive benefit-risk profile of first-line atezolizumab plus carboplatin/etoposide in extensive-stage SCLC does exist and further support this regimen as a new standard of care is warranted [17].

Other therapies approved by the FDA for the treatment of SCLC include topotecan (a topoisomerase I poison, approved for the second-line setting with response rate of 24\% [15]), while in the third-line setting, nivolumab and pembrolizumab, both programmed cell death-1 (PD-1) inhibitors have been approved [15]

Numerous attempts have been made to identify novel therapeutic targets for the treatment of SCLC.

\section{What are the current pre-clinical models?}

Several models to interrogate SCLC pre-clinically have been developed and are summarized in Box 1. In the following sections, we describe the current available models and the limitations associated with each.

\subsection{Established cell lines}

In 1971, the first established SCLC cell line was described [24]. Since then, many SCLC cell lines have been established and earlier estimates suggest that at least 300-400 lung cancer cell lines (encompassing both SCLC \& NSCLC) exist [25], and the most commonly used are provided in Table 1

Cell lines established from SCLC tumors have traditionally been seen as a basic research tool, useful for hypothesis and pre-clinical drug testing (Table 2). In general, all established cell lines (including SCLC) have significant issues as regards
Box 1. Brief descriptions of the currently existing SCLC models.

1 Established Cell Lines. A cell line is an immortalized permanently established cell culture derived from patients that will proliferate indefinitely given appropriate fresh medium and space [18].

2 Primary Cell Lines. Primary cells are taken directly from the tissue and processed to establish them under optimized culture conditions. Some primary cells will spontaneously immortalize at which point they become an established cell line [19]. Others however will not and because they have not been immortalized they will eventually senesce or stop dividing.

3 Spheroids. Multicellular spheroids are three-dimensional spherical cellular aggregates that can be generated using either established cell lines or primary cell lines [38].

4 Organoids. These are three-dimensional cell clusters with near-native microanatomy that arise from self-organizing mammalian pluripotent or adult stem cells grown in vitro $[20,21,35]$.

5 Ex Vivo Lung Models. An acellular lung model in which all cells are removed from a rat heart and lung block, and then tumor cells are reintroduced and maintained using perfusion in a bioreactor [44].

6 Cell Reprogramming. SCLC like tumors have been generated from either lung progenitor cells derived from human embryonic stem cells, or by forced overexpression of critical transcription factors in primary normal human bronchial epithelial cells.

7 Standard Xenografts. There are various models but all involve the injection of human cancer cells into immunocompromised mice, either subcutaneously, orthotopically, or systemically [67].

8 Distant Organ Metastasis models. These models often involve orthotopic transplantation of cell lines, which subsequently develop metastases to distant organs [22].

9 Syngeneic models. Such models are essentially homografts derived from immortalized mouse cancer cell lines which originated from the same inbred strain of mice. A classic example in lung cancer is the Lewis lung cancer model [23]

10 Genetically Engineered Mouse Models (GEMMs). In these models, manipulating the genomes of mice to have genetic alterations that characterize human tumors such as those found in SCLC, de novo tumors are formed in vivo [89].

11 Patient Derived Xenografts (PDXs). In these models resected human tumors are directly engrafted into immune-deficient mice, and subsequently by serial transplantation between mice [89].

12 Circulating Tumor cell derived explants (CDX). In these models circulating tumor cells (CTCs) isolated from a patient's blood form tumors when engrafted into immune-deficient mice and like PDXs can be maintained by serial transplantation [98].

their use in pre-clinical models. This problem with established cell lines was exemplified recently by a study demonstrating the significant issue of clonal evolution in breast cancer cell lines during long-term culture, resulting in significant cell line heterogeneity which can result in drastically different drug responses between clones $[26,27]$. Studies in other tumor types have shown that the epigenetic makeup of established cell lines show a distinct subset of genes which acquire de novo DNA methylation in cell lines which is not present in primary tumors [28], which may affect interpretation of cellular responses to new therapeutic agents tested in these cell lines.

SCLC tumor cell lines are no exception and some of the issues that have emerged over the years include the fact that (a) they exhibit genetic instability or drift during long-term passage, and (b) there is lack of interaction with other non-tumor components such as stromal, vascular, or inflammatory cells [25].

While pharmacogenomics profiling involving large collections of cancer cell lines have proven to be mostly reproducible, some discrepancies regarding drug sensitivity emerge [27], as exemplified by the study of Ben-David et al. [27], 
Table 1. SCLC cell lines frequently used in pre-clinical studies. Most frequently used SCLC cell lines stratified based on the new proposed molecular subtyping [9] incorporating neuroendocrine features and differential gene expression. This table is derived from data provided in $[9,129]$.

\begin{tabular}{|c|c|c|c|c|}
\hline & \multicolumn{2}{|c|}{ Neuroendocrine } & \multicolumn{2}{|c|}{ Non-Neuroendocrine } \\
\hline \multirow[t]{2}{*}{ Classification } & SCLC-A & SCLC-N & SCLC-Y & SCLC-P \\
\hline & 'Classic' & 'Variant' & 'YAP1' & 'POU2F3' \\
\hline Genomic Profile & $T P 53^{m u t} / R B 1^{m u t}$ & $T P 53^{m u t} / R B 1^{\text {mut }}$ & $T P 53^{\text {mut }} / R B 1^{\text {wt-enriched }}$ & $T P 53^{m u t} / R B 1^{m u t}$ \\
\hline \multirow{5}{*}{ Transcriptional Profile } & $A S C L 1^{\text {high }}$ & $A S C L 1^{\text {variable }}$ & $A S C L 1^{\text {low }}$ & $A S C L 11^{\text {low }}$ \\
\hline & NEUROD1 $1^{\text {low }}$ & NEUROD ${ }^{\text {high }}$ & NEUROD1 $1^{\text {low }}$ & NEUROD1 $1^{\text {low }}$ \\
\hline & INSM1 ${ }^{\text {high }}$ & INSM $7^{\text {high }}$ & INSM $7^{\text {low }}$ & INSM1 $1^{\text {low }}$ \\
\hline & $L-M Y C^{h i g h}$ & C-MYChigh & $Y A P 1^{\text {high }}$ & POU2F3 $3^{\text {high }}$ \\
\hline & & & & \\
\hline Protein Expression (IHC) & $\pi T F-1^{\text {high }} / C-M Y C^{\text {low }}$ & $\Pi T F-1^{\text {low }} / C-M Y C^{h i g h}$ & & \\
\hline \multirow{29}{*}{ Cell Lines associated with each subtype } & $\mathrm{NCl}-\mathrm{H} 1930$ & CORL-24 & $\mathrm{NCl}-\mathrm{H} 196$ & $\mathrm{NCl}-\mathrm{H} 211$ \\
\hline & $\mathrm{NCl}-\mathrm{H} 1963$ & $\mathrm{NCl}-\mathrm{H} 524$ & $\mathrm{NCl}-\mathrm{H} 2286$ & $\mathrm{NCl}-\mathrm{H} 526$ \\
\hline & COR-L47 & $\mathrm{NCl}-\mathrm{H} 1694$ & $\mathrm{NCl}-\mathrm{H} 1341$ & COR-L311 \\
\hline & $\mathrm{NCl}-\mathrm{H} 1436$ & DMS-273 & SW-1271 & $\mathrm{NCl}-\mathrm{H} 1048$ \\
\hline & $\mathrm{NCl}-\mathrm{H} 2196$ & HCC-33 & $\mathrm{NCl}-\mathrm{H} 1339$ & \\
\hline & SHP-77 & $\mathrm{NCl}-\mathrm{H} 446$ & DMS-114 & \\
\hline & $\mathrm{NCl}-\mathrm{H} 1105$ & CPC-N & $\mathrm{NCl}-\mathrm{H} 841$ & \\
\hline & $\mathrm{NCl}-\mathrm{H} 2029$ & $\mathrm{NCl}-\mathrm{H} 82$ & SBC-5 & \\
\hline & CORL-51 & $\mathrm{NCl}-\mathrm{H} 2171$ & & \\
\hline & $\mathrm{NCl}-\mathrm{H} 510$ & SCLC-21 H & & \\
\hline & COR-L95 & $\mathrm{NCl}-\mathrm{H} 2227$ & & \\
\hline & $\mathrm{NCl}-\mathrm{H} 146$ & COR-L279 & & \\
\hline & COR-L88 & $\mathrm{NCl}-\mathrm{H} 2066$ & & \\
\hline & $\mathrm{NCl}-\mathrm{H} 660$ & & & \\
\hline & $\mathrm{NCl}-\mathrm{H} 889$ & & & \\
\hline & $\mathrm{NCl}-\mathrm{H} 1618$ & & & \\
\hline & $\mathrm{NCl}-\mathrm{H} 2141$ & & & \\
\hline & DMS-454 & & & \\
\hline & $\mathrm{NCl}-\mathrm{H} 1184$ & & & \\
\hline & $\mathrm{NCl}-\mathrm{H} 1876$ & & & \\
\hline & DMS-153 & & & \\
\hline & $\mathrm{NCl}-\mathrm{H} 69$ & & & \\
\hline & COLO-668 & & & \\
\hline & $\mathrm{NCl}-\mathrm{H} 1836$ & & & \\
\hline & $\mathrm{NCl}-\mathrm{H} 209$ & & & \\
\hline & DMS-79 & & & \\
\hline & $\mathrm{NCl}-1092$ & & & \\
\hline & $\mathrm{NCl}-\mathrm{H} 2081$ & & & \\
\hline & DMS-53 & & & \\
\hline
\end{tabular}

which demonstrated that drastically different drug responses can occur between cell line clones. Such a situation has also been observed in SCLC in a recent in vitro study using $n=63$ SCLC cell lines which found that there was no correlation between patient treatment histories and sensitivities to FDA approved SCLC treatments (Etoposide and topotecan) [29].

As such studies involving SCLC cell lines while useful, should take into account the issues raised above and potentially include some of the other pre-clinical models discussed below.

\subsection{Primary cell lines}

As surgical resection of SCLC is rare, the majority of early information regarding cytogenetics abnormalities in SCLC was derived using short-term culture of primary cells and cell lines [30]. This has now of course been superseded by recent genome sequencing of primary tumors isolated at surgery [31], but is important in the historical context.

One of the advantages of primary cells is that they can be used to derive patient-derived xenografts (discussed in depth in a later section) (Table 2). However, one major limitation of the use of primary cells cultured in dishes is that if you generate and propagate these SCLC primary cells in standard 2D culture (involving standard growth conditions such as serum) a group of tumor-specific genes that are found to be expressed in both primary SCLC and xenografts is lost during this transition to tissue culture and cannot be regained when the tumors are reestablished as secondary xenografts [32]. More recently, Drapkin et al. [33] determined that short-term cultures may overcome this limitation and found that treatments of short-term cultures (STCS) of primary cells from established PDX models correlated with patient responses to experimental therapy [33,34].

\subsection{Moving cell culture from two dimensions (2D) to three dimensions (3D)}

One significant issue with the common culture of SCLC cell lines and primary cells is that often they are grown on a flat surface, such as the bottom of a petri dish or flask, and whilst convenient cells in the body do not naturally grow in a 2D fashion. Methods to grow cells in 3D have been developed such as spheroids and organoids (Table 2). The terminology spheroid and organoid are often used interchangeably yet there are distinct differences between them.

At their simplest spheroids can be viewed as consisting of cell aggregates generated from a single cell type or from a multicellular mixture of cells. Organoids on the other are 


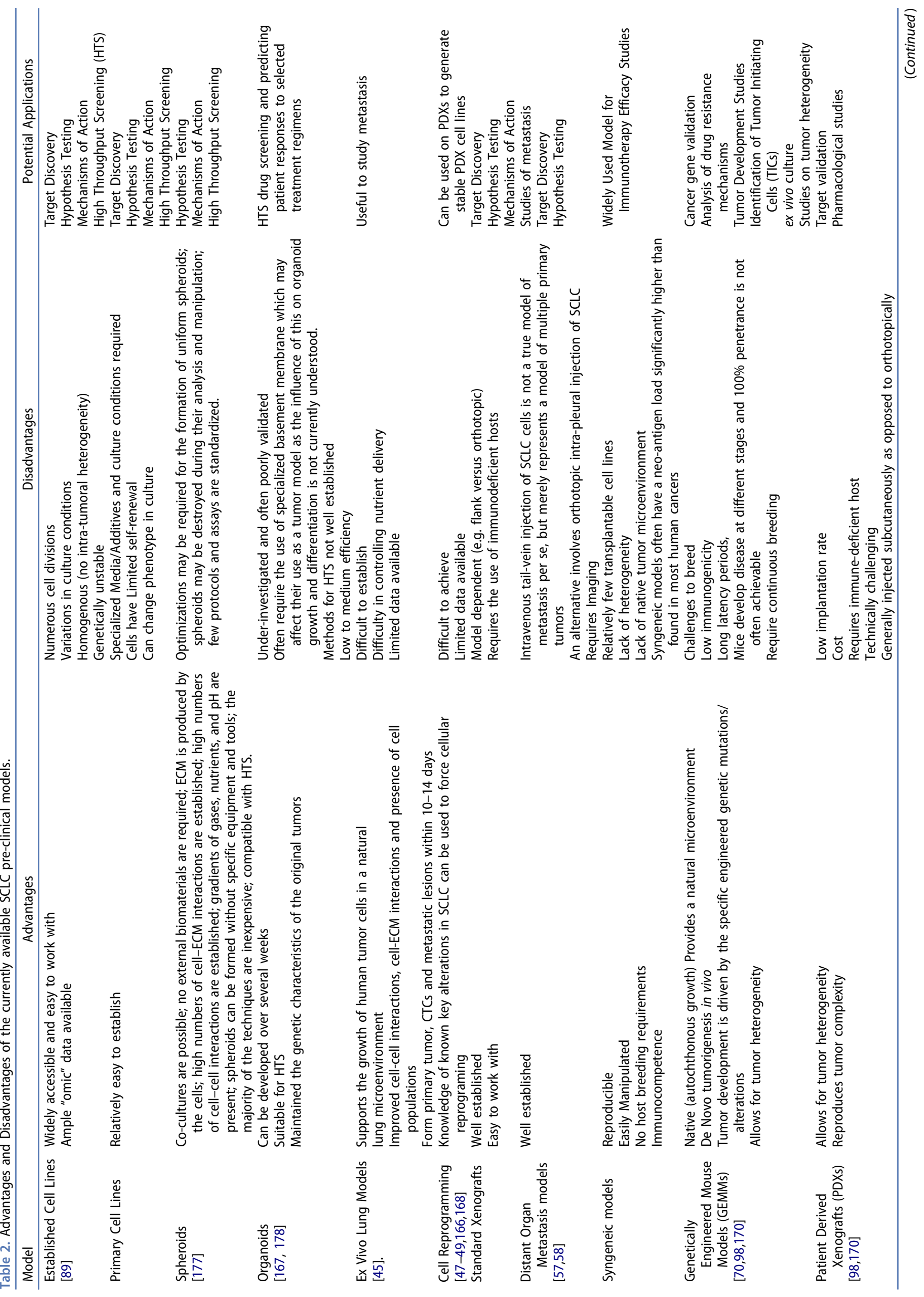




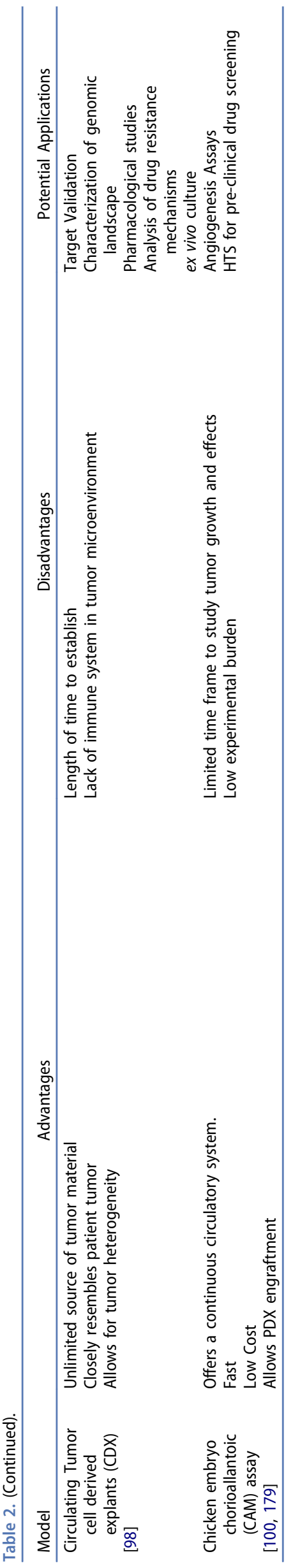


established or derived from stem cells [35], and reflect a very accurate microanatomy to the organ that they represent. There are two critical differences between the two, namely (a) internal developmental processes drive organoid formation, spheroids develop primarily via cell-to-cell adhesion; and (b) long-term culture/expansion of cells requires an immature stem cell population to replenish dying cells. As such, organoids maintain a population of stem cells during in vitro culture, which guarantees their long-term viability.

The culture of SCLC as spheroids was originally used with established SCLC cell lines, as they were thought to mimic in some degree SCLC micro-metastases [36]. Since then, a subpopulation of cells with cancer-stem like properties (such as tumorsphere formation) was identified in primary cells isolated from SCLC tumors [37]. It has now been shown that circulating tumor cells (CTCs) isolated from the blood of patients with recurrent SCLC can be cultured as tumorspheres $[38,39]$. Compared to the same cells grown as single-cell suspensions, these tumorspheres showed enhanced resistance to topotecan and epirubicin [38]. One potential limitation of deriving tumorspheres this way is that the multicellular spheroids formed from CTCs rely on the assumption that they remain largely identical to the original tumors, but this has not been fully validated [38]. Nevertheless, given the fidelity observed for patient-derived xenografts generated using CTCS (called CDXs - please see Section 2.11) it would appear that tumorspheres derived from SCLC CTCs would indeed be similar to the primary tumor.

Tumor organoids represent a novel new technique as a pre-clinical model (Table 2), particularly when primary cells derived from the patient's tumor are used to generate what is called a patient-derived organoid or PDO [40]. PDO models have several advantages over preexisting models, including conserving the molecular and cellular composition of the original tumor [41]. Moreover, there is some evidence that PDOs can better maintain the primary and tumor cell characteristics such as gene stability, heterogeneity, and the pathological features of the primary tumors in long-term culture than established cell lines and PDXs [32,40]. Thus, organoids have advantages over the traditional model and in vitro tumor model. These advantages highlight the tremendous potential of tumor organoids in personalized cancer therapy, particularly preclinical drug screening, and predicting patient responses to selected treatment regimens $[35,40,41]$.

Organoids studies of SCLC are not very common. Initial development of organoid cultures from lung cancer were first described in abstract form in 2017, when 13 lung cancer patient tissue organoids were described [42] and included some from SCLC. The organoids were compared with their human tumors histological and genetic profiles. In this regard, the SCLC organoids showed a typical neuroendocrine morphology, and maintained the genetic characteristics of the original tumors including TP53 and RB mutation. Moreover, the cancer organoids showed stronger tumor-forming capacity than direct graft of tumor tissue, and when grown as organoids had resistance to various anticancer treatments [42]. The same group recently published a more detailed protocol for growing SCLC organoids on a microfluidic-based platform for drug sensitivity testing [43]. In this matrigel-based droplet system, SCLC cultures assemble after $72 \mathrm{~h}$ into 3D organoid structures ranging from thin-walled cystic structures to compact spherical masses [43]. Targeted exome sequencing between the organoids and parent tissue showed shared mutations [43]. The potential clinical utility of this system was demonstrated by using these organoids to test drug sensitivity, in this instance using the standard first-line agents cisplatin and etoposide [43]. This would appear to be the first easy to use, cost-effective, and clinically relevant organoidbased system for direct drug sensitivity testing in SCLC [43].

\subsection{Ex vivo lung $4 D$ model}

Basically, this is an ex vivo acellular lung model, created by removing all of the cells from a rat heart and lung block (Table 2). It therefore retains a natural lung matrix maintaining its three-dimensional architecture, including perfusable vascular beds and preserved airways, including the basement membranes of the alveolar septa. When tumor cells are placed into the trachea, they form nodules in the lung matrix [44]. While this technology has been shown to be suitable for studies of SCLC [45], no data currently exists on the use of this pre-clinical model to validate any potential SCLC therapeutic targets.

\subsection{Cellular reprogramming/transdifferentiation models}

Two recent papers have shown how SCLC can be generated by forced reprogramming of cells. In the past conditions have been established for differentiating human embryonic stem cells (hESCs) into lung progenitor cells [46] (Table 2). Using this methodology, and taking advantage of the current knowledge regarding key proteins in SCLC, Chen et al. [47] found that by inhibiting Notch, RB1, and TP53, they could generate significant numbers of Pulmonary neuroendocrine cells (PNECs), the cells suspected of being the putative precursors to SCLC cells. Furthermore, these PNECs when transplanted into immunocompromised mice formed tumors with SCLC characteristics [47].

Prior to this, Park et al. [48] had used lentivirus-based transformation of normal human bronchial epithelial cells (NHBEs) to generate cells which when xenografted into immunocompromised mice formed tumors with SCLC features. The methodology involved five targets and utilized a dominantnegative TP53 (P); expression of myristoylated AKT to inhibit PTEN (A); knockdown of RB1 (R); and overexpression of c-MYC (C) and $\mathrm{BCl} 2$ (B) (called PARCB) $[48,49]$. One limitation of this particular methodology is that all 5 genetic manipulations were required in order to achieve SCLC development, whereas it is well established that only subsets of SCLC contain these particular mutations/alterations $[48,49]$.

\subsection{Standard xenograft models}

The most commonly used tumor xenograft model in cancer research involves subcutaneous flank injection into immunocompromised mice [50], and xenografts of SCLC have been used since the $1980 \mathrm{~s}$ [51,52], and continue to be used extensively to the present [53] (Table 2). 


\subsection{Standard orthotopic models}

Some of the first orthotopic models for SCLC were described in the $1990 \mathrm{~s}[54,55]$. More recently orthotopic models combining luciferase tags have been developed [56,57]; and in one instance several xenograft models (subcutaneous cell line vs orthotopic cell line vs subcutaneous PDX vs distant organ metastasis) have been interrogated simultaneously [58] (Table 2).

\subsection{Distant organ metastasis models}

The ability of SCLC cells to leave the primary tumor and establish inoperable metastases is a major cause of death and a serious impediment to successful therapy [13]. As such, distant organ metastasis models of SCLC have been developed to allow for pre-clinical interrogation of the efficacy of drugs in this situation (Table 2). The first models used tailvein injection leading to metastases to the liver, kidneys, lymph nodes, and bone marrow [59,60]. A follow-up study of several cell SCLC lines found that although all cell lines tested (SBC-5, SBC-3, SBC-3/ADM, H69, H69/VP) formed metastatic nodules in multiple organs (liver, kidney, and lymph nodes), only SBC-5 cells reproducibly developed bone metastases [61-64].

One disadvantage of the methodology used in the previous studies is that that simple use of intravenous tail-vein injection of SCLC cells is not a true model of metastasis per se, but is merely a model of multiple primary tumors. As such, orthotopic implantation of the primary tumor followed by the subsequent development of metastases would be a more relevant pre-clinical model of SCLC. In this regard, distant metastases were observed when orthotopic intra-pleural injection of SCLC was conducted in athymic nude mice [65]. A similar approach was also used by Nomoto and colleagues, where orthotopic implantation of a GFP-tagged (green fluorescent protein) SCLC cell line (DMS273-GFP) into the lung, resulted in distant metastases to bone, brain, and lymph node (metastases common to SCLC patients) [66]. Likewise, Taromi et al. also used intrathoracic injection of H69-Luc-GFP cells to develop a metastatic model of SCLC with metastases to the liver, bone, brain, adrenal glands, and kidney [57]. In a different approach, another distant metastasis model described involving intracardiac injection of a luciferase (luc) tagged SCLC cell line (lucH82) into NSG (NOD-scid gamma) mice also led to metastasis to the liver, ovaries, head, and bone [58].

\subsection{Syngeneic models}

Syngeneic murine models entail the injection of immunologically compatible cancer cells into immunocompetent mice (Table 2). The availability of syngeneic models to study lung cancer is very limited, and the best known in lung cancer is the Lewis lung carcinoma (LLC) model [67]. To our knowledge, there have been very few reports of syngeneic SCLC mouse models. The earliest was developed using HPV-E6/E7 transgenic mice, where two mouse SCLC cell lines PPAP-9 and PPAP 10, reform tumors when injected into syngeneic mice [68]. More recently a syngeneic model of SCLC in genetically engineered mice (GEMM) was described [69] (and are discussed in greater detail in the next section)

Early experiments sacrificed the animals after a set period (usually 5 weeks post inoculation) and used macroscopic dissection or X-Ray radiography to detect overt metastases.

Subsequently, most studies have utilized either GFPtagged or Luciferase-tagged SCLC cells to monitor for the presence of metastases. Such studies use either Bioluminescence imaging (BLI) or optical tomography to assess for metastases. Studies such as those by Herbst and colleagues [65] have attempted to determine if these manipulations affect the growth, metastatic spread, and testing the efficacy of chemotherapeutic agents of these SCLC metastases models. Their conclusions were that such models had close correlation between the existing clinical data suggesting that these models could be predictive of results in the clinical setting, and that the manipulations used to generate and monitor the models did not affect the results in any meaningful way [65].

\subsection{Genetically Engineered Mice Models (GEMM)}

GEMMs are non-patient-derived cancer models often achieved by manipulating one or more genes (Table 2). Until recently, progress in this area was limited, but more recent technological developments have led to advanced mouse models that closely recapitulate the human cancer in terms of genetic composition, interactions with the tumor microenvironment, metastasis, drug response, and drug resistance [70]. With the establishment that loss of $R b$ and $p 53$ are almost universally inactivated in SCLC [9], the first GEMM for SCLC was derived using a strategy to inactivate both genes and established in 2003 [71]. Two additional models were then developed incorporating triple-knockouts, the first involving $R b / p 53$ and $p 130$ $[9,72,73]$, the second involving knockout of Pten [73,74].

The $R b / p 53 / p 130$ knockout GEMM (also known as the TCKO model) has been used to further investigate the roles that two other transcription factors associated with SCLC (NEUROD1 and ASCL1) play in this cancer revealing discrete genomic landscapes and gene expression programs that underpin the heterogeneity seen in SCLC [75].

GEMM models have been used to show that MYC family members are key driver gene in SCLC. The first described was a model derived by Anton Berns group using re-derived embryonic stem cells (GEMM-ESCs) in the Rb/p53 GEMM [76].

Having identified that MYC-L is an important element in SCLC, studies using the TCKO model revealed a population of long-term tumor-propagating cells (TPCs) with high expression of EpCAM and CD24, and elevated MYC activity which could be targeted using Bromo- and Extra- Terminal domain (BET) inhibitors [77]. Other studies have also used an $R b / p 53 /$ Pten knockout GEMM, to conduct long-time longitudinal study of CTCs in animals undergoing over 4 days of treatment with a BET inhibitor [78]. Support for the critical role-played by MYC family members and in particular $\mathrm{Mycl}$ has come from other GEMM derived $\mathrm{Mycl}$ models such as the $p R b^{\text {lox/lox }}, p 53^{\text {lox/lox }}, p 130^{\text {lox/lox }}$, $\mathrm{Mycl}^{\text {lox/lox }}$ derived by $\mathrm{Kim}$ et al. [79], and the $p R b^{f / f f}, p 53^{f / / f l}$, MycT58A $A^{\text {LSL/LSL }}$ strain $[80,81]$. 
The importance of these models is that their use has identified novel candidate targets such as Aurora Kinase [80], and that Mycldriven tumors are susceptible to arginine depletion [53].

Another transcription factor commonly altered in SCLC is NFIB. Originally identified in an analysis of the $p R b^{f / f l}, p 53^{f l / f l}$ model by Tyler Jacks and colleagues [82], subsequent studies in a $p R b^{f l / f l}, p 53^{f / f l} p 130^{f l / f l}$ GEMM demonstrated that NFIB promotes metastasis via changes in the chromatin landscape of these tumors [83]. GEMMs designed to overexpress NFIB have been developed confirming the oncogenic role of NFIB in SCLC $[84,85]$.

Most recently, a GEMM involving Crebbp deletion in the $p R b / p 53$ background was shown to be a potent tumor suppressor in SCLC, and inactivation of CREBBP enhances responses to histone deacetylase inhibitors [86], a finding validated in SCLC cells, where CREBBP-mutated but not wild-type cells showed significantly lower IC50 values after treatment with a histone deacetylase inhibitor (HDACi) [87].

One of the advantages associated with GEMM models is that they can closely mimic the tumoral heterogeneity that is often observed in SCLC. In this regard, this can lead to the identification of novel therapeutic avenues such as the identification of the potential to target MYC overexpressing SCLC with either BET inhibitors [77], Aurora kinase inhibitors [80], or through arginine depletion [53]. In addition, these models have also been used to examine the differential sensitivity SCLC has to cisplatin [88].

A major limitation of GEMMs in particular for germline GEMMs is that the development of these models is 'time consuming, laborious, and expensive' [70]. Another disadvantage lies in the fact that in order to maintain these expensive models they require continuous breeding. This comes with an associated risk for genomic diversification or genomic evolution. It has been estimated that on the basis of spontaneous mutation rates, in the wild-type setting 0.96 deleterious germline mutations should arise each generation. This number will obviously be much higher in genomically unstable mice, and as colony maintenance of GEMMs relies on inbreeding, it is estimated that there is a $25 \%$ chance for a new mutation to consequently become homozygous and thus fixed in the population [89].

\subsection{Patient-derived xenografts}

PDX models from resected SCLC have been well established. In these models, tumors are directly engrafted into immunedeficient mice, and subsequently by serial transplantation between mice [89] (Table 2). The importance of these models is that they show both genomic and functional fidelity to the original tumors particularly with respect to sensitivity to standard therapy regimens such as etoposide and platinum (EP) [33] and to identify biomarkers predictive of chemoresistance [90]. In the study by Drapkin et al., upregulation of an MYC expression signature was associated with resistance to EP [33]. Moreover, such models have been used in a Phase II clinical trial setting in SCLC [91].

In addition to PDX models, CTC derived xenografts called CDX have been established [92]. These models have been shown to closely resemble the donor's original tumor, and mirror patient response to therapy (Table 2). Moreover, the ability to derive CDX models from blood samples opens up the approach to allowing the generation of serial longitudinal models from the same patient throughout the course of their treatment $[34,93]$. Such a strategy has been successfully used by Drapkin et al., to recapitulate the evolving drug sensitivities in a patient [33], and also to identify novel potential therapeutic approaches in both chemo-naïve and chemo-refractory SCLC patients [93-95].

Given the current potential for the use of CDXs and PDXs in SCLC therapy in the clinical setting [91], how might this impact or affect our attempts to follow the $3 \mathrm{R}$ initiative? Proposed 60 years ago, this initiative attempts to Replace, Reduce, and Refine the way that animals are used in research [96]. In this regard, the suggestion that for SCLC, the one mouse, one patient paradigm is worth exploring. First proposed by Malaney et al. [97], this model envisages the implantation of patient tumor samples in mice for subsequent use in drug efficacy studies. This would then allow for identification of a personalized therapeutic regimen for each patient, eliminating the cost and toxicity associated with non-targeted chemotherapeutic measures [97]. This would appear to be ideal for SCLC, yet one of the problems that may prevent this in a real-life setting is that often 'the time frame for the generation of these models often exceeds the life span of the donor patient making the "one mouse, one patient" paradigm incompatible for SCLC' [98]. In this regard, an alternative may therefore be the short-term culture of CTCs for ex vivo analyses of clinical therapeutic responses [99]. Such a strategy has recently been demonstrated by Caroline Dive and colleagues, where short-term ex vivo culture of CDX cells was utilized to develop a platform capable of screening for novel treatments [34]. Because of the limited utility of CDX models for direct patient therapy assessments, the direct culture of CTCs is being evaluated for this purpose [34]. However, the technical issue of the low numbers of CTCs in a blood draw has yet to be resolved. Moreover, such a strategy may skew toward patients with a high burden of disease.

\subsection{Chicken embryo chorioallantoic (CAM) assay}

The chick chorioallantoic membrane (CAM) assay has been suggested as a cost-effective versatile platform to conduct rapid PDX preclinical studies [100], with the potential to test multiple targeted therapies within 5-10 days of engraftment (Table 2). Successful engraftment of patient tumor tissue has been reported for several tumor types with take rates of up to $100 \%$ reported in some instances [100]. Very early initial studies have shown that lung cancer tissues can be successfully implanted in the CAM assay [101,102]. The tissues transplanted were described as either lung undifferentiated carcinoma [101], or squamous cell carcinoma [102]. Whilst to our knowledge no PDX studies of SCLC in the CAM assay have currently been described, there has been one SCLC study examining angiogenesis utilizing the $\mathrm{NCl}$ H446 cell line [103]. This suggests that the CAM assay may therefore have utility within the SCLC setting particularly regarding rapid analysis of PDX-based studies. 


\section{Validation of therapeutic targets}

It has been discussed in the previous sections novel potential therapies have been identified from the development of new preclinical models of SCLC. In the following sections, we will discuss how pre-clinical models have helped to identify some of these new therapeutic vistas for the treatment of SCLC.

\section{1. $M Y C$}

Of the several recurrent genetic aberrations identified in SCLC, the MYC family genes (MYC, MYCL, and MYCN) have emerged as oncogenic drivers that may constitute novel therapeutically tractable targets [104]. Using the pre-clinical models discussed above various studies have identified that alterations to the MYC family may render SCLC sensitive to either Aurora Kinase inhibitors [104,105], or to BET inhibitors [106-110] (Figure 1, Table 3). Subgroup analysis of c-MYC by IHC in archival tumor biopsies from a Phase II trial (NCT02038647) of the Aurora Kinase inhibitor Alisertib \pm paclitaxel in SCLC suggests that tumors with high c-MYC expression may indeed be susceptible to this compound [111], but caution is indicated as the number of samples in this subgroup analysis was restricted to $\mathrm{n}=33$ and further studies are therefore warranted) (Table 3). In a more recent development, a Crispr-based approach in
SCLC cell lines and xenografts has identified that loss of $p R b$ in SCLC renders them hyperdependent on Aurora B kinase, and as such amenable to Aurora B kinase-specific inhibitors [112]. In the same issue, Buchanan and colleagues identified a synthetic lethal interaction with RB1 and Aurora Kinase A [113]. Identifying which patients will respond to Aurora Kinase inhibitors is therefore becoming increasingly important. In this regard, a proteomic-based approach of SCLC identified two major subgroups characterized as either high TTF-1/low cMYC, or low TTF- $1 /$ high cMYC. This low TTF- $1 /$ high cMYC subgroup was confirmed as being predictive of responsiveness to Aurora Kinase inhibitors [114] (Table 3).

\subsection{NOTCH/DLL3}

The comprehensive profiling of tumors by George et al. identified the Notch pathway as being significantly affected in SCLC [31]. DLL3 is a Notch inhibitory ligand whose expression is found in $\sim 85 \%$ of SCLCs, with minimal to absent surface expression in normal lungs and has led to the development of several DLL3 targeting approaches [115] (Figure 1, Table 3). Studies in preclinical models up to and including PDXs all suggest that DLL3 could be both an excellent biomarker and therapeutic target in SCLC [58,116-118]. However, in a recent Phase II study of one of these agents Rova-T (Rovalpituzumab

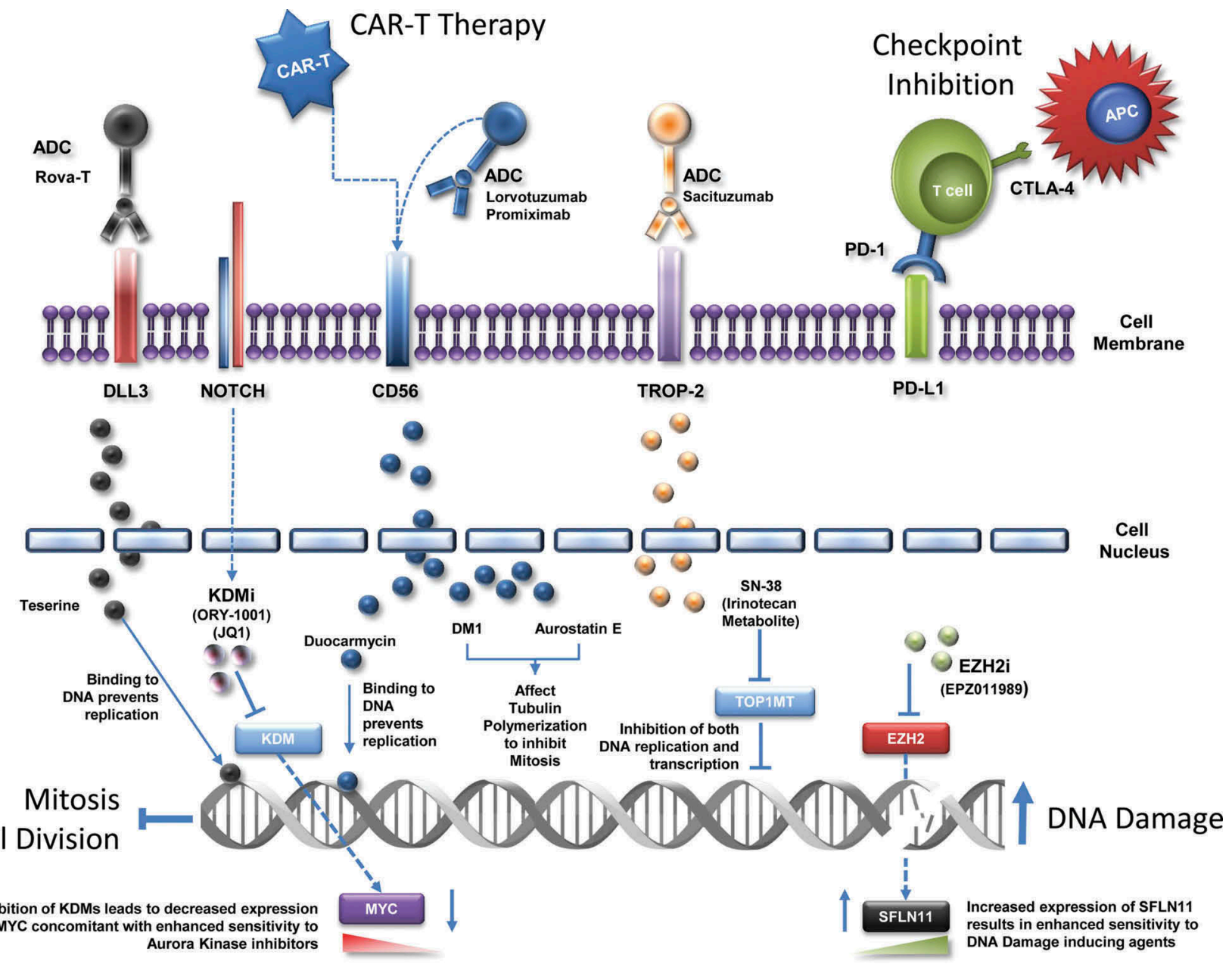

Figure 1. Targets currently under investigation in SCLC. 


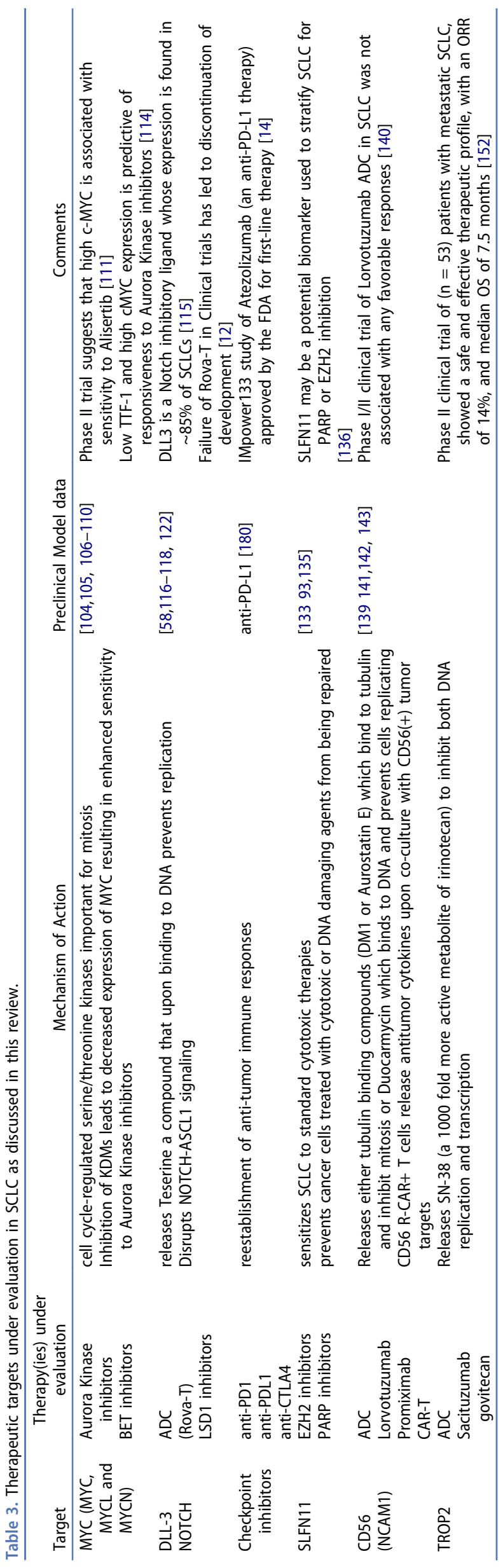


Teserine) (Figure 1), $\mathrm{n}=339$ patients were assessed for DLL3 by IHC, and DLL3-high and DLL3-positive tumors were seen in 238 (70\%) and 287 (85\%) patients, respectively [119]. Unfortunately, the results of this trial were mostly unpromising with modest clinical activity that was associated with grade 3-5 adverse events seen in 213 (63\%) patients [119]. A second Phase III trial comparing this agent with Topotecan (TAHOE) for the second-line treatment of patients with high DLL3 $(\geq 75 \%)$ extensive-stage SCLC was put on hold as shorter overall survival (OS) was reported for the Rovalpituzumab arm compared with the control arm of topotecan therapy. A further phase III study which was evaluating Rova-T as a first-line maintenance therapy for advanced SCLC, compared to placebo (MERU) also recently failed, as interim data from the study demonstrated no survival benefit for patients treated with Rova-T. On the basis of all these negative trial data Rova-T development has subsequently been discontinued [12].

DLL3 expression was also recently assessed in a CTC-driven biomarker study of SCLC patient responses to etoposide/platinum [120]. Remarkably it emerged that in this study of $n=108$ treatment-naïve patients, baseline samples were taken from all patients, after one chemotherapy cycle $(n=68$ patients; post-fir st cycle sample) and at the time of disease progression, before the initiation of second-line treatment ( $n=48$ patients; disease progression sample). The expression of DLL3, cytokeratins (CK), CD45, and vimentin (Vim) was characterized on the isolated CTCs from these samples. The most important finding was that prior to treatment, $74.1 \%$ of patients had detectable $\mathrm{DLL}^{+} / \mathrm{CD} 45^{-} \mathrm{CTCs}$. One-treatment cycle significantly decreased both the detection rate $(p<0.001)$ and the absolute number $(p<0.001)$ of the $\mathrm{DLL}^{+} / \mathrm{CD} 45^{-}$CTCs and were associated with (a) significantly decreased progression-free survival at baseline and (b) with significantly decreased overall survival on disease progression [120]. Despite the apparent set-backs with DLL3 targeting agents, a recent study using cell lines and patient PDX models identified an LSD1-NOTCH-ASCL1 axis that was sensitive to LSD1 inhibitors [121] (Figure 1, Table 3), confirming an earlier study in SCLC cell lines and xenografts that had identified LSD1 as a therapeutic target in SCLC [122]. As such, the use of DLL3 as a biomarker may allow the stratification of patients into trials involving LSD1/NOTCH inhibitors moving forward (Table 3).

\subsection{Onco-immunotherapy (checkpoint inhibitors)}

At some point, tumors manage to evade our immune system often by expressing signals that inhibit the anti-tumor immune response [123]. 'The scientific turning point for cancer immunotherapy came with the understanding that $\mathrm{T}$ cell immune responses are controlled through on and off switches, so-called immune checkpoints that protect the body from possibly damaging immune responses' [124]. Blockade of these checkpoints has emerged as a new paradigm for the treatment of cancer, including SCLC [125]. The most advanced inhibitors target the following checkpoints: CTLA4 (Cytotoxic T Lymphocyte-Associated 4); PD-1 (programmed death 1 receptor) and its ligand programmed death-ligand 1 (PD-L1) (Figure 1, Table 3).
As previously mentioned in the introduction, the results of the IMpower133 study of Atezolizumab (an anti-PD-L1 therapy) have been approved by the FDA for first-line therapy in extensive-stage SCLC [14]. Similar encouraging results have also been observed in the first-line setting for the anti-PD-1 checkpoint inhibitor Durvalumab as part of the CASPIAN Phase III trial evaluating the efficacy of this agent in combination with platinum-etoposide, with or without tremelimumab (an anti-CTLA4) in treatment-naïve extensive-stage SCLC [126].

Checkpoint inhibitors are also showing promise within the second-line setting that has come from data arising from the Phase Ib KEYNOTE-028 basket trial of Pembrolizumab (anti-PD1), which demonstrated a tolerable safety profile with an OS of 9.8 months at median follow-up [127]. More recently, a pooled analysis of two trials KEYNOTE-028 and KEYNOTE-158 of patients with previously treated recurrent/ metastatic small-cell lung cancer (SCLC) treated with two-ormore therapies found that the median duration of response was not reached (range, 4.1-35.8+ months), and that $61 \%$ of responders had responses lasting $\geq 18$ months [128], which supports the potential use of pembrolizumab within the thirdline or salvage therapy setting, and has resulted in a priority review designation by the FDA for SCLC patients following progression after $\geq 2$ prior lines of therapy [129].

It must be noted that other trials of checkpoint inhibitors in SCLC have not had the same success rate as the ones described above, and the potential confounding factors have been comprehensively reviewed recently by Reguart et al. [129]. For example, compared with non-small cell lung cancer (NSCLC), levels of PD-L1 are generally low in SCLC [15]. In a recent development, DNA-damaging agents have now been shown to enhance the expression of the checkpoint inhibitor target PD-L1 and enhance anti-tumorigenic CD8 + cytotoxic T-cells, dendritic cells, and M1 macrophage populations in an SCLC model suggesting novel new therapeutic approach and regimens to treat SCLC $[130,131]$.

\subsection{SLFN11 and the DNA damage response}

High expression of SLFN11 has been linked with the response to DNA-damage-inducing chemotherapies in many cancers $[2,111]$.

An in-depth DNA methylation analysis of SCLC identified that dense clustering of high-level methylation occurred in CpG islands which was correlated with high expression of the histone methyltransferase gene EZH2. Moreover, pharmacological inhibition of EZH2 in a patient PDX was found to inhibit tumor growth [132]. Building on this observation, Poirier and colleagues then used paired SCLC chemo-naïve and chemo-resistant PDX models to identify that in the resistant tumors, EZH2 had epigenetically downregulated SLFN11 [133] (Figure 1). Combining standard cytotoxic therapies with an $\mathrm{EZH} 2$ inhibitor subsequently prevented both the emergence of acquired resistance and augmented chemotherapeutic efficacy in both the chemo-sensitive and chemo-resistant models of SCLC [133] (Table 3). Expression of SLFN11 has since been shown to correlate with response to poly ADP ribose polymerase (PARP) inhibitors such as Talazoparib, and IHC expression levels of SLFN11 could be used as a predictor of Talazoparib response [134]. Additional studies of PARP inhibitors using preclinical PDX and CDX models have 
confirmed their potential utility in combination with either radiotherapy [135], or via WEE1 inhibitors [93] (Table 3).

In this regard, in a Phase II clinical trial of SCLC which examined the combination of the alkylating agent Temozolomide in combination with the PARP inhibitor Veliparib found that no significant difference in PFS was observed in unstratified patients, but ORR was significantly higher in patients receiving TMZ/veliparib compared with TMZ/placebo (39\% v 14\%; P =.016). Critically, however, if patients were examined for SLFN11 expression, significantly prolonged PFS (5.7 v 3.6 months; $\mathrm{P}=.009)$ and OS (12.2 v 7.5 months; $\mathrm{P}=.014)$ were observed in patients treated with TMZ/veliparib who had SLFN11-positive tumors [136]. These results suggest that SLFN11 could potentially be used to stratify SCLC into appropriate treatment arms for therapy with either PARPi or epigenetic targeting using EZH2 inhibition (Table 3).

\subsection{CD56}

CD56 (also known as neural cell adhesion molecule 1, NCAM1) is a membrane glycoprotein that was initially shown to be useful in the diagnosis of SCLC $[137,138]$. More recently, however, both antibody-drug conjugates (ADC) and chimeric antigen $\mathrm{T}$ cell (CAR-T) approach to target CD56 have been assessed in SCLC (Table 3, Figure 1).

The first agent developed to target CD56 was Lorvotuzumab mertansine an ADC comprising an anti-CD56 antibody linked via a cleavable disulfide linker to the tubulin-binding maytansinoid DM1 (Figure 1), which showed good pre-clinical activity in animal models of SCLC [139]. However, a Phase I/II clinical trial in combination with carboplatin/etoposide for patients with extensivestage SCLC was associated with only modest improvements in patient tumor responses, but with significant additional toxicities most notably a higher incidence of serious infections with fatal outcomes, and it was recommended that this combination should not be considered for further development [140] (Table 3). Two additional ADCs have been developed utilizing the anti-CD56 antibody Promiximab coupled either with Duocarmycin (a DNA alkylating agent) [141], or Monomethyl auristatin E (a highly toxic antimitotic drug) [142] (Figure 1), both of which showed preclinical activity in animal xenograft models (Table 3). At present, there do not appear to be any clinical trials running for either of these ADCs in SCLC.

A CAR-T approach has recently been reported in which the engineered CD56 R-CAR+ T cells were found to be capable of SCLC tumor cells in in vitro co-cultures and inhibit tumor growth in vivo when tested against CD56+ human xenograft models [143] (Figure 1, Table 3).

\subsection{Trop-2}

Trop-2, also known as epithelial glycoprotein-1, gastrointestinal antigen 733-1, membrane component surface marker-1, and tumor-associated calcium signal transducer- 2 is a transmembrane glycoprotein that is generally upregulated across all tumors (including SCLC) compared to normal cells [144], and is essential for anchorage-independent cell growth and tumorigenesis $[145,146]$. Subsequently, antibodies targeting Trop- 2 were been developed and subsequently Trop-2-targeted ADC (Figure 1). Of these, the most studied is sacituzumab govitecan (IMMU-132) an ADC targeting Trop-2 coupled with SN-38 (a 1000 fold more active metabolite of irinotecan) [147-149] (Table 3). It has recently achieved FDA breakthrough therapy status for the treatment of metastatic triple-negative breast cancer (mTNBC) $[150,151]$. Sacituzumab govitecan has also been examined in a Phase II clinical trial of $(n=53)$ patients with metastatic SCLC, showing a safe and effective therapeutic profile, and the ORR was 14\%, with a median OS of 7.5 months [152] (Table 3), and it will interesting to see if future studies of this agent in SCLC patients continue to show clinical benefit.

\section{Conclusion}

We have come a long way in the development of pre-clinical models in SCLC. A major barrier to the lack of progress in SCLC continues to be an incomplete understanding of the heterogeneity displayed by SCLC patients' tumors, and the absence of biomarkers that could guide selection of personalized therapeutic strategies [114]. Despite this, whilst identification of novel biomarkers and candidate therapeutic targets have indeed been identified, the resulting clinical trials of these agents have not yet made any major breakthroughs in treatment options for patients with SCLC. Continued development of the novel pre-clinical models discussed in the previous sections coupled with new syntheses based on large-scale reanalysis of SCLC data will provide new vistas and avenues of patient stratification which will ultimately result in definite breakthroughs for therapy $[9,99,111,153]$.

\section{Expert opinion}

Huge strides have been made in the past two decades in our understanding of SCLC based in no small part on the development of the pre-clinical models discussed in the previous sections. Despite this, the treatment options available to SCLC patients remain limited, and overall survival remains dismal.

Moving forward, how can we improve on this? Are there any alternatives that we could use? For example, do we need pre-clinical models? In a recent analysis of RNA-Seq data from small-cell neuroendocrine cancers (SCNCs) of which SCLC belongs, it was found that (a) SCNCs have a strongly convergent expression signature; and (b) As these tumors progress from adenocarcinoma to SCNCs the tumors become increasingly independent of their tissue of origin, becoming more similar to each other than to adenocarcinomas of different tissues [154]. Moreover, from a drug screening perspective, it was subsequently shown that SCNCs demonstrated common sensitivity profiles that overlap with hematological cancers, which may allow or guide treatment options beyond tissuespecific-targeted therapies [154].

Given the difficulties that researchers face regarding the development and heterogeneity seen in SCLC, can we correctly mimic SCLC? Rather than developing even more GEMMs or PDX/CDX models is there an opportunity to take the new knowledge gained from these and instead develop integrated 
cancer tissue engineering models of SCLC to enable precision medicine treatments [155].

Synthetic lethality describes a situation whereby for two genes that interact, disruption of either gene alone is viable but when both genes are simultaneously disrupted the net result is a loss of cell viability [156]. Synthetic lethality screening aims to identify novel therapeutic targets and increased genetic interaction networks for targeting cancer [157]. Recently a synthetic lethal screen in SCLC identified that HDAC6 and its corresponding inhibitor ricolinostat elicited synergistic effects with BET inhibitors in SCLC [158]. In addition, it was found that Natural Killer (NK) cells are critical to this response, suggesting that these innate immune lymphoid cells play a role in SCLC tumor treatment response [158], and the suggestion that immunoepigenetic combination therapies may become a new paradigm for the treatment of cancer including SCLC [159]. Critically the first major breakthrough in the treatment of SCLC would appear to be in the oncoimmunology setting where checkpoint inhibitors have been shown to have clinical benefit and may yet be approved in the first-line setting in combination with chemotherapy $[14,129]$. From analyses, it would appear that Tumor Mutational Burden (TMB) may have the ability to predict patient response for checkpoint inhibitors [160,161]. Intriguingly, neoantigen-directed immune escape in NSCLC was recently shown to involve an epigenetic mechanism (hypermethylation of genes that contain neoantigenic mutations) [162], suggesting that immunoepigenetic strategies may become important moving forward in both the selection and treatment of patients with SCLC.

Novel technologies such as clustered regularly interspaced short palindromic repeats (CRISPR) based screening strategies for synthetic lethality are now beginning to identify new subsets of tumors sensitive to targeting agents such as the approach used by Oser et al. [112] to identify that SCLC with loss of Rb1 are hyperdependent on Aurora Kinase B. In a similar strategy, using a CRISPR-based activation model, Sos and colleagues demonstrated that MYC (but not MYCL or MYCN) repressed BCL2 transcription via interaction with MIZ1 and DNMT3a [163]. As a consequence of this loss of $B C L 2$, cells were found to have elevated apoptotic priming, intrinsic genotoxic stress, and susceptibility to DNA damage checkpoint inhibitors. Moreover, a combination of combined AURK and CHK1 inhibition substantially prolonged the survival of mice bearing MYC-driven SCLC beyond that of combination chemotherapy, confirming the potential role of MYC as a candidate that may allow for genotype-based selection of targeted therapeutics in SCLC [163].

Can we identify better biomarkers to predict patients who will respond to novel therapeutics? One emerging biomarker that may be useful to assist in stratification may be to include TTF immunohistochemistry in SCLC patient workup along with actionable targets such as DLL3 and c-MYC which may aid in the correct stratification of patients for treatment $[114,164]$. Moreover, low-TTF expression may also indicate sensitivity to additional targets such as DNA Damage Repair agents, PLK inhibitors, etc. [114]. Cells that were TTF-high were found to be sensitive to $\mathrm{BCl}-2$ inhibitors which have been shown to have activity in pre-clinical PDX models of SCLC, when combined with rapamycin [165]. High TTF expression has also been shown to be a potential surrogate marker for DLL3 expression, and could potentially be used to additionally stratify patients with DLL3-positive tumors [114], and this observation was recently validated in a separate cohort of SCLC [164].

One of the significant barriers to individualized therapy for SCLC remains the lack of biological material to allow for detailed analysis. In this regard, the length of time for developing PDX or CDX models is a rate-limiting step. The emergence of ex vivo cultures of CTCs may prove to be a critical element in the treatment paradigm of SCLC [99], and the development of new technologies such as microfluidic chipbased growth of patient organoids [43] may allow for a more nuanced analysis of patient response to therapy and/or identification of individualized personalized therapeutic treatment regimens. Another potential area where advances may occur involves the use of conditional reprogramming to generate stable PDX derived cell lines [166] suitable for organoid development and the establishment of patient-derived organoid biobanks $[167,168]$.

What therefore would be the ideal model for SCLC therapy testing or is there one? Despite being described as small-cell, one size does not fit all in the case of this difficult to treat cancer. As discussed in previous sections the development of PDX or CDX models in mice is costly and time-consuming and does not make them easily accessible to personalized patient therapeutic testing. In this regard, it may be useful to develop organoid-based testing strategies using CTCs or alternatively, CAM assay strategies could be considered as an alternative for personalized approaches to therapy.

Given the potential breakthroughs emerging for the use of onco-immunological targeting of SCLC, the current pre-clinical models (including PDXs and CDXs) have limitations. In this instance, pre-clinical models that involve humanized mice that recapitulate the human immune system may yet prove to be an essential development to come [169-171]. In this regard, such models have been used to test oncoimmunological agents such as checkpoint inhibitors in NSCLC [172-174], but we are currently unaware of any such studies in SCLC. However, whilst such a strategy looks promising it is not without limitations as the immune system generated in these models is not the same as the cancer patients (that is, whilst the PDX/CDX itself may be similar to the cancer patient, unless the humanized mouse system utilizes PBMCs from the patient, then the immune component will not truly match that of the patient). Nevertheless, we look forward to seeing studies in SCLC utilizing such approaches for preclinical analysis of onco-immunological therapies to treat this cancer.

Blood-based analysis of SCLC may yet prove to be critical to allow clinicians treat patients with SCLC. Recent analyses of circulating free DNA (cfDNA) longitudinally in patients with SCLC [175] raises the possibility that both strategies (cfDNA and isolation of CTCs for ex vivo expansion and testing) could be combined to enhance the treatment options for patients with SCLC. Moreover, the recent development of a bloodbased methodology to assess TMB in NSCLC (bTMB) [176] suggests that the age of the so-called liquid biopsy is about to emerge in our treatment of SCLC. 


\section{Funding}

This paper was not funded.

\section{Declaration of Interest}

The authors have no relevant affiliations or financial involvement with any organization or entity with a financial interest in or financial conflict with the subject matter or materials discussed in the manuscript. This includes employment, consultancies, honoraria, stock ownership or options, expert testimony, grants or patents received or pending, or royalties.

\section{Reviewer Disclosures}

Peer reviewers on this manuscript have no relevant financial relationships or otherwise to disclose.

\section{ORCID}

Steven G. Gray (D) http://orcid.org/0000-0002-5850-6392

\section{References}

Papers of special note have been highlighted as either of interest $(\cdot)$ or of considerable interest (..) to readers.

1. Govindan R, Page N, Morgensztern D, et al. Changing epidemiology of small-cell lung cancer in the United States over the last 30 years: analysis of the surveillance, epidemiologic, and end results database. J Clin Oncol. 2006 Oct 1;24(28):4539-4544.

2. Gazdar AF, Bunn PA, Minna JD. Small-cell lung cancer: what we know, what we need to know and the path forward. Nat Rev Cancer. 2017 Nov 10;17(12):765.

3. Farago AF, Keane FK. Current standards for clinical management of small cell lung cancer. Transl Lung Cancer Res. 2018 Feb;7(1):69-79.

4. Socinski MA, Smit EF, Lorigan P, et al. Phase III study of pemetrexed plus carboplatin compared with etoposide plus carboplatin in chemotherapy-naive patients with extensive-stage small-cell lung cancer. J Clin Oncol. 2009 Oct 1;27(28):4787-4792.

5. Ettinger DS, Aisner J. Changing face of small-cell lung cancer: real and artifact. J Clin Oncol. 2006 Oct 1;24(28):4526-4527.

6. Zelen M. Keynote address on biostatistics and data retrieval. Cancer Chemother Rep. 1973 Mar 3;4(2):31-42.

7. Shepherd FA, Crowley J, Van Houtte P, et al. The international association for the study of lung cancer lung cancer staging project: proposals regarding the clinical staging of small cell lung cancer in the forthcoming (seventh) edition of the tumor, node, metastasis classification for lung cancer. J Thorac Oncol. 2007 Dec;2 (12):1067-1077.

8. Nicholson AG, Chansky K, Crowley J, et al. The International association for the study of lung cancer lung cancer staging project: PROPOSALS for the revision of the clinical and pathologic staging of small cell lung cancer in the forthcoming eighth edition of the TNM classification for lung cancer. J Thorac Oncol. 2016 Mar;11 (3):300-311.

9. Rudin CM, Poirier JT, Byers LA, et al. Molecular subtypes of small cell lung cancer: a synthesis of human and mouse model data. Nat Rev Cancer. 2019 May;19(5):289-297.

- An excellent review and commentary which also suggests a new nomenclature for SCLC subtypes based on differential expression of four key transcription regulators

10. Oronsky B, Reid TR, Oronsky A, et al. What's new in SCLC? A review. Neoplasia. 2017 Oct;19(10):842-847.

11. Byers LA, Rudin CM. Small cell lung cancer: where do we go from here? Cancer. 2015 Mar 1;121(5):664-672.

12. Mullard A. Cancer stem cell candidate Rova-T discontinued. Nat Rev Drug Discov. 2019 Oct;18(11):814.
13. van Meerbeeck JP, Fennell DA, De Ruysscher DK. Small-cell lung cancer. Lancet. 2011 Nov 12;378(9804):1741-1755.

14. Horn L, Mansfield AS, Szczesna A, et al. First-Line atezolizumab plus chemotherapy in extensive-stage small-cell lung cancer. $\mathrm{N}$ Engl J Med. 2018 Dec 6;379(23):2220-2229.

.. The data from this trial led to the first approval by the FDA of a checkpoint inhibitor in the treatment of SCLC within the firstline setting

15. Tian $Y$, Zhai $X$, Han A, et al. Potential immune escape mechanisms underlying the distinct clinical outcome of immune checkpoint blockades in small cell lung cancer. J Hematol Oncol. 2019 Jun 28;12(1):67.

16. Zhou K, Zhou J, Huang J, et al. Cost-effectiveness analysis of atezolizumab plus chemotherapy in the first-line treatment of extensive-stage small-cell lung cancer. Lung Cancer. 2019 Apr;130:1-4.

17. Mansfield AS, Kazarnowicz A, Karaseva N, et al. Safety and patient-reported outcomes of atezolizumab, carboplatin, and etoposide in extensive-stage small-cell lung cancer (IMpower133): a randomized phase I/III trial. Ann Oncol. 2020 Feb;31(2):310-317.

18. Ulrich $A B$, Pour PM. Cell lines. In: Brenner $S$, Miller JH, editors. Encyclopedia of genetics. New York: Academic Press; 2001. p. 310-311.

19. Berendsen HH, de Leij L, de Vries EG, et al. Characterization of three small cell lung cancer cell lines established from one patient during longitudinal follow-up. Cancer Res. 1988 Dec 1;48(23):6891-6899.

20. Kretzschmar K, Clevers H. Organoids: modeling development and the stem cell niche in a dish. Dev Cell. 2016 Sep 26;38(6):590-600.

21. Clinton J, McWilliams-Koeppen P. Initiation, expansion, and cryopreservation of human primary tissue-derived normal and diseased organoids in embedded three-dimensional culture. Curr Protoc Cell Biol. 2019 Mar;82(1):e66.

22. Gomez-Cuadrado L, Tracey N, Ma R, et al. Mouse models of metastasis: progress and prospects. Dis Model Mech. 2017 Sep 1;10 (9):1061-1074.

23. van Lamsweerde AL, Henry N, Vaes G. Metastatic heterogeneity of cells from Lewis lung carcinoma. Cancer Res. 1983 Nov;43 (11):5314-5320.

24. Oboshi S, Tsugawa S, Seido T, et al. A new floating cell line derived from human pulmonary carcinoma of oat cell type. Gan. 1971 Dec;62(6):505-514.

25. Gazdar AF, Gao B, Minna JD. Lung cancer cell lines: useless artifacts or invaluable tools for medical science? Lung Cancer. 2010 Jun;68 (3):309-318.

26. Hynds RE, Vladimirou $E$, Janes $S M$. The secret lives of cancer cell lines. Dis Model Mech. 2018 Nov 16;11(11).DOI: 10.1242/ dmm.037366.

27. Ben-David U, Siranosian B, Ha G, et al. Genetic and transcriptional evolution alters cancer cell line drug response. Nature. 2018 Aug;560(7718):325-330.

- Important paper showing how cell line evolution at the genetic and epigenetic level affects responses to drugs

28. De Carvalho DD, Sharma S, You JS, et al. DNA methylation screening identifies driver epigenetic events of cancer cell survival. Cancer Cell. 2012 May 15;21(5):655-667.

29. Polley $E$, Kunkel $M$, Evans $D$, et al. Small cell lung cancer screen of oncology drugs, investigational agents, and gene and microRNA expression. J Natl Cancer Inst. 2016 Oct;108(10).DOI: 10.1093/jnci/ djw122

30. Heighway J, Betticher D. Lung: small cell cancer. Atlas Genet Cytogenet OncolHaematol. 2004;8(3):257-259.

31. George J, Lim JS, Jang SJ, et al. Comprehensive genomic profiles of small cell lung cancer. Nature. 2015 Aug 6;524(7563):47-53.

32. Daniel VC, Marchionni L, Hierman JS, et al. A primary xenograft model of small-cell lung cancer reveals irreversible changes in gene expression imposed by culture in vitro. Cancer Res. 2009 Apr 15;69 (8):3364-3373.

33. Drapkin BJ, George J, Christensen CL, et al. Genomic and functional fidelity of small cell lung cancer patient-derived xenografts. Cancer Discov. 2018 May;8(5):600-615. 
.- Important study showing that PDX xenografts retain the essential characteristics (genomic and otherwise) of the original tumor

34. Lallo A, Gulati S, Schenk MW, et al. Ex vivo culture of cells derived from circulating tumour cell xenograft to support small cell lung cancer research and experimental therapeutics. $\mathrm{Br} J$ Pharmacol. 2019 Feb;176(3):436-450.

- Study demonstrating the utility of CTCs for both generation of CDX models and for further additional ex vivo culture

35. Bleijs $M$, van de Wetering $M$, Clevers $H$, et al. Xenograft and organoid model systems in cancer research. Embo J. 2019 Aug 1;38(15):e101654.

- Excellent review concerning xenograft and organoid model systems in research

36. Olabiran Y, Ledermann JA, Marston NJ, et al. The selection of antibodies for targeted therapy of small-cell lung cancer (SCLC) using a human tumour spheroid model to compare the uptake of cluster 1 and cluster w4 antibodies. Br J Cancer. 1994 Feb;69 (2):247-252.

37. Wang $P$, Gao Q, Suo Z, et al. Identification and characterization of cells with cancer stem cell properties in human primary lung cancer cell lines. PLoS One. 2013;8(3):e57020.

38. Klameth L, Rath B, Hochmaier $M$, et al. Small cell lung cancer: model of circulating tumor cell tumorospheres in chemoresistance. Sci Rep. 2017 Jul 13;7(1):5337.

39. Hamilton G, Hochmair M, Rath B, et al. Small cell lung cancer: circulating tumor cells of extended stage patients express a mesenchymal-epithelial transition phenotype. Cell Adh Migr. 2016 Jul 3;10(4):360-367.

40. Yang L, Yang S, Li X, et al. Tumor organoids: from inception to future in cancer research. Cancer Lett. 2019 Jul;10(454):120-133.

41. Aboulkheyr Es H, Montazeri L, Aref AR, et al. Personalized Cancer medicine: an organoid approach. Trends Biotechnol. 2018 Apr;36 (4):358-371. DOI: 10.1016/j.tibtech.2017.12.005. Epub 2018 Jan 20.

42. Kim M, Chun S-M, Mun $\mathrm{H}$, et al. Abstract 4832: establishment of lung cancer organoid lines as a new preclinical model for lung cancer. Cancer Res. 2017;77(13 Supplement):4832.

43. Jung DJ, Shin $\mathrm{TH}$, Kim M, et al. A one-stop microfluidic-based lung cancer organoid culture platform for testing drug sensitivity. Lab Chip. 2019 Sep 7;19(17):2854-2865.

44. Mishra DK, Thrall MJ, Baird BN, et al. Human lung cancer cells grown on acellular rat lung matrix create perfusable tumor nodules. Ann Thorac Surg. 2012 Apr;93(4):1075-1081.

45. Mishra DK, Miller RA, Pence KA, et al. Small cell and non small cell lung cancer form metastasis on cellular $4 D$ lung model. $B M C$ Cancer. 2018 Apr 18;18(1):441.

46. Huang SX, Green MD, de Carvalho AT, et al. The in vitro generation of lung and airway progenitor cells from human pluripotent stem cells. Nat Protoc. 2015 Mar;10(3):413-425.

- Demonstration of the ability to generate SCLC-like tumors from stem cells

47. Chen HJ, Poran A, Unni AM, et al. Generation of pulmonary neuroendocrine cells and SCLC-like tumors from human embryonic stem cells. J Exp Med. 2019 Mar 4;216(3):674-687.

- Paper showing that normal human epithelial tissues can be reprogrammed into neuroendocrine cancer lineages.

48. Park JW, Lee JK, Sheu KM, et al. Reprogramming normal human epithelial tissues to a common, lethal neuroendocrine cancer lineage. Science. 2018 Oct 5;362(6410):91-95.

49. Gazdar AF, Minna JD. Small cell lung cancers made from scratch. J Exp Med. 2019 Mar 4;216(3):476-478.

50. Richmond A, Su Y. Mouse xenograft models vs GEM models for human cancer therapeutics. Dis Model Mech. 2008 Sep-Oct; 1 (2-3):78-82.

51. Gazdar AF, Carney DN, Nau MM, et al. Characterization of variant subclasses of cell lines derived from small cell lung cancer having distinctive biochemical, morphological, and growth properties. Cancer Res. 1985 Jun;45(6):2924-2930.

52. Olsson L, Sorensen HR, Behnke O. Intratumoral phenotypic diversity of cloned human lung tumor cell lines and consequences for analyses with monoclonal antibodies. Cancer. 1984 Nov 1;54 (9):1757-1765.

53. Chalishazar MD, Wait SJ, Huang F, et al. MYC-driven small-cell lung cancer is metabolically distinct and vulnerable to arginine depletion. Clin Cancer Res. 2019 Aug 15;25(16):5107-5121.

54. Kuo TH, Kubota T, Watanabe $M$, et al. Orthotopic reconstitution of human small-cell lung carcinoma after intravenous transplantation in SCID mice. Anticancer Res. 1992 Sep-Oct;12(5):1407-1410.

55. Kuo TH, Kubota $T$, Watanabe $M$, et al. Site-specific chemosensitivity of human small-cell lung carcinoma growing orthotopically compared to subcutaneously in SCID mice: the importance of orthotopic models to obtain relevant drug evaluation data. Anticancer Res. 1993 May-Jun;13(3):627-630.

56. Taromi S, Kayser G, Catusse J, et al. CXCR4 antagonists suppress small cell lung cancer progression. Oncotarget. 2016 Dec 20;7 (51):85185-85195.

57. Taromi S, Kayser G, von Elverfeldt D, et al. An orthotopic mouse model of small cell lung cancer reflects the clinical course in patients. Clin Exp Metastasis. 2016 Oct;33(7):651-660.

58. Sharma SK, Pourat J, Abdel-Atti D, et al. Noninvasive interrogation of dll3 expression in metastatic small cell lung cancer. Cancer Res. 2017 Jul 15;77(14):3931-3941.

59. Shtivelman E, Namikawa R. Species-specific metastasis of human tumor cells in the severe combined immunodeficiency mouse engrafted with human tissue. Proc Natl Acad Sci U S A. 1995 May 9;92(10):4661-4665.

60. Hanibuchi M, Yano S, Nishioka Y, et al. Therapeutic efficacy of mouse-human chimeric anti-ganglioside GM2 monoclonal antibody against multiple organ micrometastases of human lung cancer in NK cell-depleted SCID mice. Int J Cancer. 1998 Nov 9;78(4):480-485.

61. Miki T, Yano S, Hanibuchi M, et al. Bone metastasis model with multiorgan dissemination of human small-cell lung cancer (SBC-5) cells in natural killer cell-depleted SCID mice. Oncol Res. 2000;12(5):209-217.

62. Yano $S$, Zhang $H$, Hanibuchi $M$, et al. Combined therapy with a new bisphosphonate, minodronate (YM529), and chemotherapy for multiple organ metastases of small cell lung cancer cells in severe combined immunodeficient mice. Clin Cancer Res. 2003 Nov 1;9(14):5380-5385.

63. Zhang H, Yano S, Miki T, et al. A novel bisphosphonate minodronate (YM529) specifically inhibits osteolytic bone metastasis produced by human small-cell lung cancer cells in NK-cell depleted SCID mice. Clin Exp Metastasis. 2003;20(2):153-159.

64. Takeuchi S, Fukuda K, Arai S, et al. Organ-specific efficacy of HSP90 inhibitor in multiple-organ metastasis model of chemorefractory small cell lung cancer. Int J Cancer. 2016 Mar 1;138(5):1281-1289.

65. Isobe T, Onn A, Morgensztern D, et al. Evaluation of novel orthotopic nude mouse models for human small-cell lung cancer. J Thorac Oncol. 2013 Feb;8(2):140-146.

66. Sakamoto $\mathrm{S}$, Inoue $\mathrm{H}$, Ohba $\mathrm{S}$, et al. New metastatic model of human small-cell lung cancer by orthotopic transplantation in mice. Cancer Sci. 2015 Apr;106(4):367-374.

67. Kellar A, Egan C, Morris D. Preclinical murine models for lung cancer: clinical trial applications. Biomed Res Int. 2015;2015:621324.

68. Carraresi L, Martinelli R, Vannoni A, et al. Establishment and characterization of murine small cell lung carcinoma cell lines derived from HPV-16 E6/E7 transgenic mice. Cancer Lett. 2006 Jan 8;231(1):65-73.

69. Kellish P, Shabashvili D, Rahman MM, et al. Oncolytic virotherapy for small-cell lung cancer induces immune infiltration and prolongs survival. J Clin Invest. 2019 Apr 29;129(6):2279-2292.

70. Kersten $\mathrm{K}$, de Visser $\mathrm{KE}$, van Miltenburg $\mathrm{MH}_{\text {, et al. Genetically }}$ engineered mouse models in oncology research and cancer medicine. EMBO Mol Med. 2017 Feb;9(2):137-153.

71. Meuwissen R, Linn SC, Linnoila Rl, et al. Induction of small cell lung cancer by somatic inactivation of both Trp53 and Rb1 in a conditional mouse model. Cancer Cell. 2003 Sep;4(3):181-189.

72. Schaffer BE, Park KS, Yiu G, et al. Loss of p130 accelerates tumor development in a mouse model for human small-cell lung carcinoma. Cancer Res. 2010 May 15;70(10):3877-3883.

73. Gazdar AF, Savage TK, Johnson JE, et al. The comparative pathology of genetically engineered mouse models for neuroendocrine carcinomas of the lung. J Thorac Oncol. 2015 Apr;10(4):553-564. 
74. McFadden DG, Papagiannakopoulos T, Taylor-Weiner A, et al. Genetic and clonal dissection of murine small cell lung carcinoma progression by genome sequencing. Cell. 2014 Mar 13;156 (6):1298-1311.

75. Borromeo MD, Savage TK, Kollipara RK, et al. ASCL1 and NEUROD1 reveal heterogeneity in pulmonary neuroendocrine tumors and regulate distinct genetic programs. Cell Rep. 2016 Aug 2;16 (5):1259-1272.

76. Huijbers IJ, Bin Ali R, Pritchard C, et al. Rapid target gene validation in complex cancer mouse models using re-derived embryonic stem cells. EMBO Mol Med. 2014 Feb;6(2):212-225.

77. Jahchan NS, Lim JS, Bola B, et al. Identification and targeting of long-term tumor-propagating cells in small cell lung cancer. Cell Rep. 2016 Jul 19;16(3):644-656.

78. Hamza B, Ng SR, Prakadan SM, et al. Optofluidic real-time cell sorter for longitudinal CTC studies in mouse models of cancer. Proc Natl Acad Sci U S A. 2019 Feb 5;116(6):2232-2236.

79. Kim DW, Wu N, Kim YC, et al. Genetic requirement for Mycl and efficacy of RNA Pol I inhibition in mouse models of small cell lung cancer. Genes Dev. 2016 Jun 1;30(11):1289-1299.

80. Mollaoglu G, Guthrie MR, Bohm S, et al. MYC drives progression of small cell lung cancer to a variant neuroendocrine subtype with vulnerability to aurora kinase inhibition. Cancer Cell. 2017 Feb 13;31(2):270-285.

81. Zhang W, Girard L, Zhang YA, et al. Small cell lung cancer tumors and preclinical models display heterogeneity of neuroendocrine phenotypes. Transl Lung Cancer Res. 2018 Feb;7(1):32-49.

82. Dooley AL, Winslow MM, Chiang DY, et al. Nuclear factor I/B is an oncogene in small cell lung cancer. Genes Dev. 2011 Jul 15;25 (14):1470-1475.

83. Denny SK, Yang D, Chuang CH, et al. Nfib Promotes metastasis through a widespread increase in chromatin accessibility. Cell. 2016 Jul 14;166(2):328-342.

84. Semenova EA, Kwon MC, Monkhorst K, et al. Transcription factor NFIB is a driver of small cell lung cancer progression in mice and marks metastatic disease in patients. Cell Rep. 2016 Jul 19;16 (3):631-643.

85. Wu N, Jia D, Ibrahim AH, et al. NFIB overexpression cooperates with $\mathrm{Rb} / \mathrm{p} 53$ deletion to promote small cell lung cancer. Oncotarget. 2016 Sep 6;7(36):57514-57524.

86. Jia D, Augert A, Kim DW, et al. Crebbp loss drives small cell lung cancer and increases sensitivity to HDAC inhibition. Cancer Discov. 2018 Nov;8(11):1422-1437.

87. Hellwig $M$, Merk DJ, Lutz $B$, et al. Preferential sensitivity to HDAC inhibitors in tumors with CREBBP mutation. Cancer Gene Ther. 2019 May 9.

88. Bottger F, Semenova EA, Song JY, et al. Tumor heterogeneity underlies differential cisplatin sensitivity in mouse models of small-cell lung cancer. Cell Rep. 2019 Jun 11;27(11):3345-58 e4.

89. Ben-David U, Beroukhim R, Golub TR. Genomic evolution of cancer models: perils and opportunities. Nat Rev Cancer. 2019 Feb;19 (2):97-109.

90. Wang Z, Fu S, Zhao J, et al. Transbronchoscopic patient biopsy-derived xenografts as a preclinical model to explore chemorefractory-associated pathways and biomarkers for small-cell lung cancer. Cancer Lett. 2019 Jan;440-441:180-188.

91. Owonikoko TK, Zhang G, Kim HS, et al. Patient-derived xenografts faithfully replicated clinical outcome in a phase II co-clinical trial of arsenic trioxide in relapsed small cell lung cancer. J Transl Med. 2016 May 3;14(1):111.

- Important paper showing that PDXs can be used to predict clinical outcome in an actual clinical trial setting

92. Hodgkinson CL, Morrow CJ, Li Y, et al. Tumorigenicity and genetic profiling of circulating tumor cells in small-cell lung cancer. Nat Med. 2014 Aug;20(8):897-903.

- Important paper demonstrating the utility of CTCs in SCLC.

93. Lallo A, Frese KK, Morrow CJ, et al. The Combination of the PARP inhibitor olaparib and the WEE1 Inhibitor AZD1775 as a new therapeutic option for small cell lung cancer. Clin Cancer Res. 2018 Oct 15;24(20):5153-5164.
94. Potter DS, Galvin M, Brown $\mathrm{S}$, et al. Inhibition of PI3K/BMX cell survival pathway sensitizes to BH3 mimetics in SCLC. Mol Cancer Ther. 2016 Jun;15(6):1248-1260.

95. Williamson SC, Metcalf RL, Trapani F, et al. Vasculogenic mimicry in small cell lung cancer. Nat Commun. 2016 Nov;9(7):13322.

96. Tannenbaum J, Bennett BT. Russell and Burch's 3Rs then and now: the need for clarity in definition and purpose. J Am Assoc Lab Anim Sci. 2015 Mar;54(2):120-132.

97. Malaney P, Nicosia SV, Dave V. One mouse, one patient paradigm: new avatars of personalized cancer therapy. Cancer Lett. 2014 Mar 1;344(1):1-12.

98. Lallo A, Schenk MW, Frese KK, et al. Circulating tumor cells and CDX models as a tool for preclinical drug development. Transl Lung Cancer Res. 2017 Aug;6(4):397-408.

99. Blackhall F, Frese KK, Simpson K, et al. Will liquid biopsies improve outcomes for patients with small-cell lung cancer? Lancet Oncol. 2018 Sep;19(9):e470-e81.

.- Excellent review discussing the development and roles of the liquid biopsy in the management of SCLC

100. DeBord LC, Pathak RR, Villaneuva M, et al. The chick chorioallantoic membrane (CAM) as a versatile patient-derived xenograft (PDX) platform for precision medicine and preclinical research. Am J Cancer Res. 2018;8(8):1642-1660.

101. Sommers SC, Sullivan BA, Warren S. Heterotransplantation of human cancer. III. Chorioallantoic membranes of embryonated eggs. Cancer Res. 1952;Dec;12(12):915-917.

102. Kaufman N, Kinney TD, Mason EJ, et al. Maintenance of human neoplasm on the chick chorioallantoic membrane. Am J Pathol. 1956 Mar-Apr;32(2):271-285.

103. Wan J, Chai H, Yu Z, et al. HIF-1alpha effects on angiogenic potential in human small cell lung carcinoma. J Exp Clin Cancer Res. 2011 Aug 15;30:77.

104. Bragelmann J, Bohm S, Guthrie MR, et al. Family matters: how MYC family oncogenes impact small cell lung cancer. Cell Cycle. 2017 Aug 18;16(16):1489-1498.

105. Du J, Yan L, Torres R, et al. Aurora A selective inhibitor LY3295668 leads to dominant mitotic arrest, apoptosis in cancer cells and shows potent preclinical antitumor efficacy. Mol Cancer Ther. 2019 Sep 17;18:2207-2219.

106. Kato F, Fiorentino FP, Alibes $A$, et al. MYCL is a target of a BET bromodomain inhibitor, JQ1, on growth suppression efficacy in small cell lung cancer cells. Oncotarget. 2016 Nov 22;7(47):77378-77388.

107. Lam LT, Lin X, Faivre EJ, et al. Vulnerability of small-cell lung cancer to apoptosis induced by the Combination of bet bromodomain proteins and bcl2 inhibitors. Mol Cancer Ther. 2017 Aug;16 (8):1511-1520.

108. Lenhart R, Kirov $S$, Desilva $H$, et al. Sensitivity of small cell lung cancer to BET inhibition is mediated by regulation of ASCL1 gene expression. Mol Cancer Ther. 2015 Oct;14(10):2167-2174.

109. Riveiro ME, Astorgues-Xerri L, Vazquez R, et al. OTX015 (MK-8628), a novel BET inhibitor, exhibits antitumor activity in non-small cell and small cell lung cancer models harboring different oncogenic mutations. Oncotarget. 2016 Dec 20;7(51):84675-84687.

110. Wang $H$, Hong $B$, Li $X$, et al. JQ1 synergizes with the BCl-2 inhibitor ABT-263 against MYCN-amplified small cell lung cancer. Oncotarget. 2017 Oct 17;8(49):86312-86324.

111. Foy V, Schenk MW, Baker K, et al. Targeting DNA damage in SCLC. Lung Cancer. 2017 Dec;114:12-22.

112. Oser MG, Fonseca R, Chakraborty AA, et al. Cells lacking the RB1 tumor suppressor gene are hyperdependent on aurora $B$ kinase for survival. Cancer Discov. 2019 Feb;9(2):230-247.

113. Gong X, Du J, Parsons SH, et al. Aurora A Kinase inhibition is synthetic lethal with loss of the RB1 tumor suppressor gene. Cancer Discov. 2019 Feb;9(2):248-263.

114. Cardnell RJ, Li L, Sen T, et al. Protein expression of TTF1 and CMYC define distinct molecular subgroups of small cell lung cancer with unique vulnerabilities to aurora kinase inhibition, DLL3 targeting, and other targeted therapies. Oncotarget. 2017 Sep 26;8 (43):73419-73432. 
115. Leonetti A, Facchinetti F, Minari R, et al. Notch pathway in small-cell lung cancer: from preclinical evidence to therapeutic challenges. Cell Oncol (Dordr). 2019 Jun;42(3):261-273.

116. Furuta M, Sakakibara-Konishi J, Kikuchi H, et al. Analysis of DLL3 and ASCL1 in surgically resected small cell lung cancer (HOT1702). The Oncologist. 2019;24(11):e1172-e1179.

117. Owen DH, Giffin MJ, Bailis JM, et al. DLL3: an emerging target in small cell lung cancer. J Hematol Oncol. 2019 Jun 18;12(1):61.

118. Saunders LR, Bankovich AJ, Anderson WC, et al. A DLL3-targeted antibody-drug conjugate eradicates high-grade pulmonary neuroendocrine tumor-initiating cells in vivo. Sci Transl Med. 2015 Aug 26;7(302):302ra136.

119. Morgensztern D, Besse B, Greillier L, et al. Efficacy and safety of rovalpituzumab tesirine in third-line and beyond patients with DLL3-expressing, relapsed/refractory small-cell lung cancer: results from the phase II TRINITY study. Clin Cancer Res. 2019 Dec 1;25 (23):6958-6966.

120. Messaritakis I, Nikolaou M, Koinis F, et al. Characterization of DLL3-positive circulating tumor cells (CTCS) in patients with small cell lung cancer $(\mathrm{SCLC})$ and evaluation of their clinical relevance during front-line treatment. Lung Cancer. 2019 Sep;135:33-39.

121. Augert A, Eastwood E, Ibrahim AH, et al. Targeting NOTCH activation in small cell lung cancer through LSD1 inhibition. Sci Signal. 2019 Feb 5;12:567.

122. Takagi S, Ishikawa Y, Mizutani A, et al. LSD1 inhibitor T-3775440 inhibits SCLC cell proliferation by disrupting Isd 1 interactions with snag domain proteins INSM1 and GFI1B. Cancer Res. 2017 Sep 1;77 (17):4652-4662.

123. Mahoney KM, Rennert PD, Freeman GJ. Combination cancer immunotherapy and new immunomodulatory targets. Nat Rev Drug Discov. 2015 Aug;14(8):561-584.

124. Hoos A. Development of immuno-oncology drugs - from CTLA4 to PD1 to the next generations. Nat Rev Drug Discov. 2016 Apr;15 (4):235-247.

125. Saleh K, Khalife-Saleh N, Kourie HR. Finally, after decades, immune checkpoint inhibitors dethroned the standard of care of small-cell lung cancer. Immunotherapy. 2019 Apr;11(6):457-460.

126. Paz-Ares L, Dvorkin $M$, Chen $Y$, et al. Durvalumab plus platinum-etoposide versus platinum-etoposide in first-line treatment of extensive-stage small-cell lung cancer (CASPIAN): a randomised, controlled, open-label, phase 3 trial. Lancet. 2019 Nov 23;394(10212):1929-1939.

127. Ott PA, Elez E, Hiret $S$, et al. Pembrolizumab in patients with extensive-stage small-cell lung cancer: results from the phase $\mathrm{Ib}$ KEYNOTE-028 study. J Clin Oncol. 2017 Dec 1;35(34):3823-3829.

- Important paper providing evidence for the use of checkpoint inhibitors in the second-line setting

128. Chung HC, Piha-Paul SA, Lopez-Martin J, et al. pembrolizumab after two or more lines of previous therapy in patients with recurrent or metastatic small-cell lung cancer: results from the KEYNOTE-028 and KEYNOTE-158 Studies. J Thorac Oncol. 2019 Dec 20. pii: S15560864(19)33850-X.

- Important paper showing potential for checkpoint inhibitors in the third-line or "salvage" setting for SCLC

129. Reguart N, Marin E, Remon J, et al. In search of the long-desired 'copernican therapeutic revolution' in small-cell lung cancer. Drugs. 2020 Jan 8;80:241-262.

130. Sen T, Rodriguez BL, Chen $L$, et al. Targeting DNA damage response promotes antitumor immunity through STING-mediated T-cell activation in small cell lung cancer. Cancer Discov. 2019 May;9 (5):646-661.

131. Sen T, Della Corte CM, Milutinovic S, et al. Combination treatment of the oral CHK1 inhibitor, SRA737 and low dose gemcitabine, enhances the effect of PD-L1 blockade by modulating the immune microenvironment in small cell lung cancer. J Thorac Oncol. 2019 Dec 1;14 (12):2152-2163.

132. Poirier JT, Gardner EE, Connis N, et al. DNA methylation in small cell lung cancer defines distinct disease subtypes and correlates with high expression of EZH2. Oncogene. 2015 Nov 26;34(48):5869-5878.
133. Gardner EE, Lok BH, Schneeberger VE, et al. Chemosensitive relapse in small cell lung cancer proceeds through an EZH2-SLFN11 axis. Cancer Cell. 2017 Feb 13;31(2):286-299.

134. Lok BH, Gardner EE, Schneeberger VE, et al. PARP inhibitor activity correlates with SLFN11 expression and demonstrates synergy with Temozolomide in small cell lung cancer. Clin Cancer Res. 2017 Jan 15;23(2):523-535.

135. Laird JH, Lok BH, Ma J, et al. Talazoparib is a potent radiosensitizer in small cell lung cancer cell lines and xenografts. Clin Cancer Res. 2018 Oct 15;24(20):5143-5152.

136. Pietanza MC, Waqar SN, Krug LM, et al. Randomized, double-blind, phase ii study of temozolomide in combination with either Veliparib or Placebo in patients with relapsed-sensitive or refractory small-cell lung cancer. J Clin Oncol. 2018 Aug 10;36(23):2386-2394.

137. Kontogianni K, Nicholson AG, Butcher D, et al. CD56: a useful tool for the diagnosis of small cell lung carcinomas on biopsies with extensive crush artefact. J Clin Pathol. 2005 Sep;58 (9):978-980.

138. Zheng G, Ettinger DS, Maleki Z. Utility of the quantitative Ki-67 proliferation index and CD56 together in the cytologic diagnosis of small cell lung carcinoma and other lung neuroendocrine tumors. Acta Cytol. 2013;57(3):281-290.

139. Whiteman KR, Johnson HA, Mayo MF, et al. Lorvotuzumab mertansine, a CD56-targeting antibody-drug conjugate with potent antitumor activity against small cell lung cancer in human xenograft models. MAbs. 2014 Mar-Apr;6(2):556-566.

140. Socinski MA, Kaye FJ, Spigel DR, et al. Phase 1/2 Study of the CD56-targeting antibody-drug conjugate Lorvotuzumab Mertansine (IMGN901) in combination with carboplatin/etoposide in small-cell lung cancer patients with extensive-stage disease. Clin Lung Cancer. 2017 Jan;18(1):68-76 e2.

141. Yu L, Lu Y, Yao Y, et al. Promiximab-duocarmycin, a new CD56 antibody-drug conjugates, is highly efficacious in small cell lung cancer xenograft models. Oncotarget. 2018 Jan 12;9(4):5197-5207.

142. Yu L, Yao Y, Wang Y, et al. Preparation and anti-cancer evaluation of promiximab-MMAE, an anti-CD56 antibody drug conjugate, in small cell lung cancer cell line xenograft models. J Drug Target. 2018 Dec;26(10):905-912.

143. Crossland DL, Denning WL, Ang S, et al. Antitumor activity of CD56-chimeric antigen receptor $\mathrm{T}$ cells in neuroblastoma and SCLC models. Oncogene. 2018 Jul;37(27):3686-3697.

144. Zaman S, Jadid H, Denson AC, et al. Targeting Trop-2 in solid tumors: future prospects. Onco Targets Ther. 2019;12:1781-1790.

145. Wang J, Day R, Dong Y, et al. Identification of Trop-2 as an oncogene and an attractive therapeutic target in colon cancers. Mol Cancer Ther. 2008 Feb;7(2):280-285.

146. Trerotola M, Cantanelli $P$, Guerra E, et al. Upregulation of Trop-2 quantitatively stimulates human cancer growth. Oncogene. 2013 Jan 10;32(2):222-233.

147. Cardillo TM, Govindan SV, Sharkey RM, et al. Humanized anti-Trop2 lgG-SN-38 conjugate for effective treatment of diverse epithelial cancers: preclinical studies in human cancer xenograft models and monkeys. Clin Cancer Res. 2011 May 15;17(10):3157-3169.

148. Cardillo TM, Govindan SV, Sharkey RM, et al. Sacituzumab Govitecan (IMMU-132), an anti-Trop-2/SN-38 antibody-drug conjugate: characterization and efficacy in pancreatic, gastric, and other cancers. Bioconjug Chem. 2015 May 20;26(5):919-931.

149. Sahota S, Vahdat LT. Sacituzumab govitecan: an antibody-drug conjugate. Expert Opin Biol Ther. 2017 Aug;17(8):1027-1031.

150. Fenn KM, Kalinsky K. Sacituzumab govitecan: antibody-drug conjugate in triple-negative breast cancer and other solid tumors. Drugs Today (Barc). 2019 Sep;55(9):575-585.

151. Bardia A, Mayer IA, Vahdat LT, et al. Sacituzumab Govitecan-hziy in refractory metastatic triple-negative breast cancer. $\mathrm{N}$ Engl J Med. 2019 Feb 21;380(8):741-751.

152. Gray JE, Heist RS, Starodub AN, et al. Therapy of small cell lung cancer (SCLC) with a Topoisomerase---inhibiting antibody-drug conjugate (ADC) targeting trop-2, sacituzumab govitecan. Clin Cancer Res. 2017 Oct 1;23(19):5711-5719. 
153. Turajlic S, Sottoriva A, Graham T, et al. Resolving genetic heterogeneity in cancer. Nat Rev Genet. 2019 Jul;20(7):404-416.

154. Balanis NG, Sheu KM, Esedebe FN, et al. Pan-cancer convergence to a small-cell neuroendocrine phenotype that shares susceptibilities with hematological malignancies. Cancer Cell. 2019 Jul 8;36(1):17-34 e7.

155. Bregenzer ME, Horst EN, Mehta $P$, et al. Integrated cancer tissue engineering models for precision medicine. PLoS One. 2019;14(5):e0216564.

156. O'Neil NJ, Bailey ML, Hieter P. Synthetic lethality and cancer. Nat Rev Genet. 2017 Oct;18(10):613-623.

157. Huang A, Garraway LA, Ashworth A, et al. Synthetic lethality as an engine for cancer drug target discovery. Nat Rev Drug Discov. 2020 Jan;19(1):23-38.

158. Liu Y, Li Y, Liu S, et al. NK cells mediate synergistic antitumor effects of combined inhibition of HDAC6 and BET in a SCLC preclinical model. Cancer Res. 2018 Jul 1;78(13):3709-3717.

- Important paper linking immunoepigenetics to SCLC.

159. Banik D, Moufarrij S, Villagra A. Immunoepigenetics combination therapies: an overview of the role of HDACs in cancer immunotherapy. Int J Mol Sci. 2019 May 7;20:9.

160. Hellmann MD, Callahan MK, Awad MM, et al. Tumor mutational burden and efficacy of nivolumab monotherapy and in combination with ipilimumab in small-cell lung cancer. Cancer Cell. 2018 May 14;33(5):853-61 e4.

161. Ricciuti B, Kravets S, Dahlberg SE, et al. Use of targeted next generation sequencing to characterize tumor mutational burden and efficacy of immune checkpoint inhibition in small cell lung cancer. J Immunother Cancer. 2019 Mar 28;7(1):87.

162. Rosenthal R, Cadieux EL, Salgado R, et al. Neoantigen-directed immune escape in lung cancer evolution. Nature. 2019 Mar;567 (7749):479-485.

- Important paper linking epigenetics with neoantigen-directed immune escape in NSCLC, and something which may in the future be linked with SCLC.

163. Dammert MA, Bragelmann J, Olsen RR, et al. MYC paralog-dependent apoptotic priming orchestrates a spectrum of vulnerabilities in small cell lung cancer. Nat Commun. 2019 Aug 2;10(1):3485.

164. Yan LX, Liu YH, Li Z, et al. Prognostic value of delta-like protein 3 combined with thyroid transcription factor-1 in small-cell lung cancer. Oncol Lett. 2019 Sep;18(3):2254-2261.

165. Gardner EE, Connis N, Poirier JT, et al. Rapamycin rescues ABT-737 efficacy in small cell lung cancer. Cancer Res. 2014 May 15;74 (10):2846-2856.

166. Borodovsky A, McQuiston TJ, Stetson D, et al. Generation of stable PDX derived cell lines using conditional reprogramming. Mol Cancer. 2017 Dec 6;16(1):177.
167. Tuveson D, Clevers $H$. Cancer modeling meets human organoid technology. Science. 2019 Jun 7;364(6444):952-955.

168. Palechor-Ceron N, Krawczyk E, Dakic A, et al. conditional reprogramming for patient-derived cancer models and next-generation living biobanks. Cells. 2019 Oct 27;8:11.

169. Chen Q, Wang J, Liu WN, et al. Cancer immunotherapies and humanized mouse drug testing platforms. Transl Oncol. 2019 Jul;12(7):987-995.

170. Olson B, Li Y, Lin Y, et al. Mouse models for cancer immunotherapy research. Cancer Discov. 2018 Nov;8(11):1358-1365.

171. Lampreht Tratar U, Horvat S, Cemazar M. Transgenic mouse models in cancer research. Front Oncol. 2018;8:268.

172. Pyo $\mathrm{KH}$, Kim JH, Lee JM, et al. Promising preclinical platform for evaluation of immuno-oncology drugs using Hu-PBL-NSG lung cancer models. Lung Cancer. 2019 Jan;127:112-121.

173. Wang $M$, Yao LC, Cheng $M$, et al. Humanized mice in studying efficacy and mechanisms of PD-1-targeted cancer immunotherapy. Faseb J. 2018 Mar;32(3):1537-1549.

174. Lin S, Huang G, Cheng L, et al. Establishment of peripheral blood mononuclear cell-derived humanized lung cancer mouse models for studying efficacy of PD-L1/PD-1 targeted immunotherapy. MAbs. 2018 Nov-Dec;10(8):1301-1311.

175. Almodovar K, lams WT, Meador CB, et al. Longitudinal cell-free DNA analysis in patients with small cell lung cancer reveals dynamic insights into treatment efficacy and disease relapse. J Thorac Oncol. 2018 Jan;13(1):112-123.

176. Wang Z, Duan J, Cai S, et al. Assessment of blood tumor mutational burden as a potential biomarker for immunotherapy in patients with non-small cell lung cancer with use of a next-generation sequencing cancer gene panel. JAMA Oncol. 2019 May 1;5(5):696-702.

177. Nunes AS, Barros AS, Costa EC, et al. 3D tumor spheroids as in vitro models to mimic in vivo human solid tumors resistance to therapeutic drugs. Biotechnol Bioeng. 2019 Jan;116 (1):206-226.

178. Drost J, Clevers HI. Organoids in cancer research. Nat Rev Cancer 2018 Jul;18(7):407-18.

179. Dunker N, Jendrossek V. Implementation of the Chick Chorioallantoic Membrane (CAM) Model in Radiation Biology and Experimental Radiation Oncology Research. Cancers (Basel). 2019 Oct 7;11(10).

180. Meder L, Schuldt P, Thelen M, Schmitt A, Dietlein F, Klein S, et al. Combined VEGF and PD-L1 Blockade Displays Synergistic Treatment Effects in an Autochthonous Mouse Model of Small Cell Lung Cancer. Cancer Res 2018 Aug 1;78(15):4270-81. 